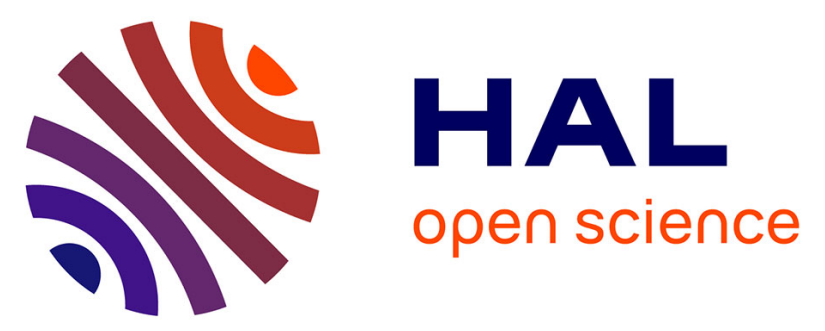

\title{
Theoretical Investigation of the Electronic Structure and Magnetic Properties of Oxo-Bridged Uranyl(V) Dinuclear and Trinuclear Complexes
}

Billel Teyar, Seddik Boucenina, Lotfi Belkhiri, Boris Le Guennic, Abdou Boucekkine, Marinella Mazzanti

\section{To cite this version:}

Billel Teyar, Seddik Boucenina, Lotfi Belkhiri, Boris Le Guennic, Abdou Boucekkine, et al.. Theoretical Investigation of the Electronic Structure and Magnetic Properties of Oxo-Bridged Uranyl(V) Dinuclear and Trinuclear Complexes. Inorganic Chemistry, 2019, 58 (15), pp.10097-10110. 10.1021/acs.inorgchem.9b01237 . hal-02278397

\section{HAL Id: hal-02278397} https://hal-univ-rennes1.archives-ouvertes.fr/hal-02278397

Submitted on 18 Nov 2019

HAL is a multi-disciplinary open access archive for the deposit and dissemination of scientific research documents, whether they are published or not. The documents may come from teaching and research institutions in France or abroad, or from public or private research centers.
L'archive ouverte pluridisciplinaire HAL, est destinée au dépôt et à la diffusion de documents scientifiques de niveau recherche, publiés ou non, émanant des établissements d'enseignement et de recherche français ou étrangers, des laboratoires publics ou privés. 
Theoretical investigation of the electronic structure and magnetic properties of oxo-bridged uranyl(V) dinuclear and trinuclear complexes

Billel Teyar, ${ }^{\mathrm{a}, \mathrm{b}}$ Seddik Boucenina, ${ }^{\mathrm{a}}$ Lotfi Belkhiri, ${ }^{\mathrm{a}}$ Boris Le Guennic, ${ }^{\mathrm{c}}$ Abdou Boucekkine, ${ }^{\mathrm{c}}$ Marinella Mazzanti ${ }^{\mathrm{d}}$

${ }^{\text {a }}$ Laboratoire de Physique Mathématique et Subatomique LPMS, Faculté des Sciences Exactes, Université des Frères Mentouri, 25017 Constantine, Algeria.

${ }^{\mathrm{b}}$ Université Ziane Achour de Djelfa, 17000 Djelfa, Algeria.

${ }^{\mathrm{c}}$ Univ Rennes, CNRS, ISCR - UMR 6226, F-35000 Rennes, France.

${ }^{\mathrm{d}}$ Institut des Sciences et Ingénierie Chimiques, Ecole Polytechnique Fédérale de Lausanne (EPFL), CH1015 Lausanne, Switzerland.

\title{
Corresponding authors
}

*Email (A. Boucekkine): abdou.boucekkine@univ-rennes 1.fr

*Email (L. Belkhiri): lotfi.belkhiri@umc.edu.dz

\begin{abstract}
The uranyl(V) complexes $\left[\mathrm{UO}_{2}(\mathrm{dbm})_{2} \mathrm{~K}(18 \mathrm{C} 6)\right]_{2}\left(\mathrm{dbm}\right.$ : dibenzoylmethanate) and $\left[\mathrm{UO}_{2}(\mathrm{~L})\right]_{3}(\mathrm{~L}$ = 2(4-Tolyl)-1,3-bis(quinolyl)malondiiminate) exhibiting diamond-shape $\mathrm{U}_{2} \mathrm{O}_{2}$ and triangularshape $\mathrm{U}_{3} \mathrm{O}_{3}$ cores respectively with $5 \mathrm{f}^{1}-5 \mathrm{f}^{1}$ and $5 \mathrm{f}^{1}-5 \mathrm{f}^{1}-5 \mathrm{f}^{1}$ configurations, have been investigated using relativistic density functional theory (DFT). The bond order and QTAIM analyses reveal that the covalent contribution to the bonding within the oxo cores is slightly more important for the $\mathrm{U}_{3} \mathrm{O}_{3}$ than for $\mathrm{U}_{2} \mathrm{O}_{2}$ one, in line with the shorter $\mathrm{U}-\mathrm{O}$ distances existing in the trinuclear complex than in the binuclear one. Using the Broken Symmetry (BS) approach combined with the B3LYP functional for the calculation of the magnetic exchange coupling constants $(J)$ between the magnetic centres, the antiferromagnetic (AF) character of these complexes was confirmed, the estimated $J$ values being respectively equal to -24.1 and $-7.2 \mathrm{~cm}^{-}$ ${ }^{1}$ for the dioxo and the trioxo species. It was found that the magnetic exchange is more sensitive to small variations of the core geometry of the dioxo species than for the trioxo one. Although the robust $A F$ exchange coupling within the $U_{x} O_{x}$ cores is generally maintained when small variations of the UOU angle are applied, a weak ferromagnetic character appears in the dioxo species when this angle is higher than $114^{\circ}$, its value for the actual structure being equal to $105.9^{\circ}$. The electronic factors driving the magnetic coupling are discussed.
\end{abstract}

Dedicated to Dr Jean-François Halet on the occasion of his $60^{\text {th }}$ birthday. 


\section{- Introduction}

In the last thirty years there has been an increasing interest in the development of molecules named 'Single Molecule Magnets' (SMMs) featuring slow relaxation of the magnetization and magnetic hysteresis of purely molecular origin ${ }^{1-8}$ owing to their potential application in quantum computing, ${ }^{9}$ high-density information storage ${ }^{10-12}$ and more recently, in molecular spintronic materials. ${ }^{13,14}$ Since the discovery of the first polynuclear manganese complex ${ }^{1}$ behaving as a single molecule magnet as a result of magnetic exchange, there is a continuous effort for the design, synthesis and characterization of new generations of molecular complexes exhibiting magnetic exchange interactions between metal centers. ${ }^{2}$ Notably, the application of single molecule magnets in information storage would only be possible if their operating temperature could be increased to practical values. Recent efforts in the field have focused on lanthanide based systems owing to their large magnetic anisotropies associated to their strong exchange coupling and magnetic blocking. ${ }^{13-15}$ Recently a mononuclear compound of a $4 f$-ion, namely the dysprosium system $\left[\mathrm{Dy}\left(\mathrm{Cp}^{i \mathrm{Pr} 5}\right)\left(\mathrm{Cp}^{*}\right)\right]^{+}\left(\mathrm{Cp}^{i \mathrm{Pr} 5}=\right.$ penta-iso-propylcyclopentadienyl; $\left.\mathrm{Cp}^{*}=\mathrm{C}_{5} \mathrm{Me}_{5}\right),{ }^{16}$ was reported that shows a magnetic hysteresis at the record temperature of 80 $\mathrm{K}$ that originates from the exceptional magnetic axiality of the single $\mathrm{Dy}^{3+}$ ion in the cyclopentadienyl ligand environment. ${ }^{12,15}$ An alternative approach to increase the temperature of the magnetic hysteresis is to obtain high-spin ground states via magnetic exchange between multiple high anisotropy lanthanide ions. This is difficult to achieve for $4 f$ systems because they tend to form ionic bonds that limit magnetic exchange coupling and can only be successfully achieved via bridging radicals. ${ }^{17-21}$ Consequently, since the discovery of the slow magnetic relaxation in the mononuclear complex $\mathrm{U}\left(\mathrm{Ph}_{2} \mathrm{BPz}_{2}\right)_{3}$, ${ }^{22}$ an increasing number of studies have been directed to develop SMMs based on actinide-containing systems. ${ }^{23-28}$ These studies include mono $^{29-38}$ and polynuclear systems $\mathrm{s}^{39-41}$ and heteropolymetallic uranium-3d metal complexes. ${ }^{42-48}$ Notably, uranium not only shows large spin-orbit coupling but in addition the more diffuse nature of $5 f$ orbitals compared to $4 f$ orbitals, ${ }^{36,40}$ is expected to allow higher $p-f$ orbital overlap and hence stronger magnetic couplings. ${ }^{23,25}$

Therefore, efforts in this area have been directed to synthesize and characterize polynuclear uranium systems, where a successful strategy in promoting electronic interactions between $5 f$ spin centers was to use covalently linked bridging ligands. ${ }^{39-46,49-60}$ Although a growing number of actinide complexes showing significant super-exchange magnetic interactions, quantifying 
the coupling constant between 5 -ion pairs is still challenging both at the experimental and theoretical levels. $^{23}$

Interestingly, the emergence of a new class of magnetic diuranium complexes with $\mathrm{U}_{2} \mathrm{E}_{2}$ core types $(\mathrm{E}=\mathrm{N}, \mathrm{O}, \mathrm{S}, \mathrm{Se}, \mathrm{Te})$, has motivated research in this area ${ }^{61,62}$ Most noteworthy, the syntheses of uranyl(V) complexes, showing new $\mathrm{UO}_{2}{ }^{+} \ldots \mathrm{UO}_{2}{ }^{+}$"cation-cation" interaction (CCI) have been reported, ${ }^{63-73}$ in which up to four $\mathrm{UO}_{2}{ }^{+}$moieties, are mutually coordinated through the oxo-ligands of an actinyl unit which interacts as an equatorial ligand with another metal center. CCI was reported to play a crucial role in the enhancement of magnetic interactions between pentavalent actinyl ions, giving rise to ferromagnetic or antiferromagnetic (AF) ordering through a super-exchange pathway. ${ }^{63-65}$ The first example of a complex containing a $\mathrm{UO}_{2}{ }^{+} \ldots \mathrm{UO}_{2}{ }^{+}$interaction, the diuranium $(\mathrm{V})\left[\mathrm{UO}_{2}(\mathrm{dbm})_{2} \mathrm{~K}(18 \mathrm{C} 6)\right]_{2}$ system $(\mathrm{dbm}=$ dibenzoylmethanate) was reported in 2008 by Mazzanti and co-workers, ${ }^{63}$ showed a diamondshaped CCI interaction with a $\mathrm{U}_{2} \mathrm{O}_{2}$ core (Scheme 1). The solid-state variable-temperature magnetic susceptibility study showed the unambiguous presence of AF coupling between the two oxo-bridged $\mathrm{U}^{\mathrm{V}}\left(\mu-\mathrm{O}_{2}\right) \mathrm{U}^{\mathrm{V}}$ uranium centers with $\mathrm{U}---\mathrm{U}$ separation of $3.462 \AA{ }^{63}$
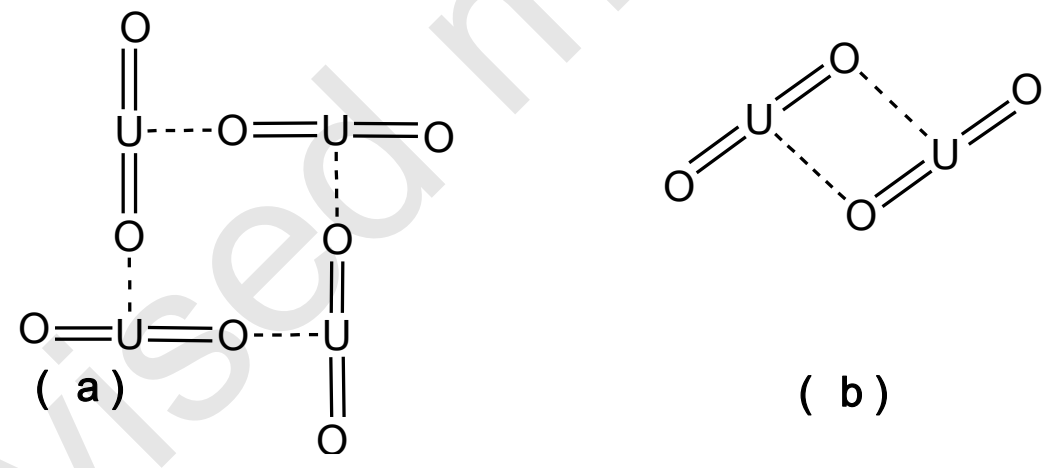

Scheme 1: T-shaped tetramer (a) and diamond-shaped dimer (b) $\mathrm{UO}_{2}{ }^{+} \ldots \mathrm{UO}_{2}{ }^{+}$exhibiting CCIs

More recently, P. L. Arnold et al. ${ }^{64}$ reported a new binuclear $\mathrm{U}^{\mathrm{V}}-\mathrm{U}^{\mathrm{V}}$ system with uranyl cis/trans-oxo arrangement namely the butterfly shaped $\left[\left(\mathrm{R}_{3} \mathrm{SiOU}^{\mathrm{V}} \mathrm{O}\right)_{2}(\mathrm{~L})\right]$ complex and showed, with the support of DFT calculations, that the $\mathrm{U}^{\mathrm{V}}(\mu-\mathrm{O})_{2} \mathrm{U}^{\mathrm{V}}$ diamond-core cluster exhibits an AF exchange coupling between the two $5 \mathrm{f}^{1}-5 \mathrm{f}^{1}$ centers with a short $\mathrm{U}---\mathrm{U}$ separation of $3.355(7)$ $\AA$ via super-exchange interactions.

Subsequently, in 2014, K. Meyer and co-workers. ${ }^{71}$ reported new dinuclear $\mathrm{U}^{\mathrm{V}} / \mathrm{U}^{\mathrm{V}}, \mathrm{U}^{\mathrm{IV}} / \mathrm{U}^{\mathrm{IV}}$ and mixed-valent $\mathrm{U}^{\mathrm{V}} / \mathrm{U}^{\mathrm{IV}}$ bis( $\mu$-oxo)-bridged complexes, all exhibiting diamond-core shaped $[\mathrm{U}(\mu$ - 
$\left.\mathrm{O})_{2} \mathrm{U}\right]$ structural motifs but remarkably different magnetic behaviors, depending on the uranium oxidation state. The pentavalent dinuclear $\mathrm{U}^{\mathrm{V}} / \mathrm{U}^{\mathrm{V}}\left[\left\{\left((\mathrm{nP}, \mathrm{MeArO})_{3} \operatorname{tacn}\right) \mathrm{U}^{\mathrm{V}}\right\}_{2}(\mu-\mathrm{O})_{2}\right]$ species ( $\operatorname{tacn}=$ triazacyclononane, $\mathrm{nP}=$ neopentyl $)$, is characterized by a relatively short $\mathrm{U}---\mathrm{U}$ distance of 3.422(3) A. We showed that relativistic DFT computations could rationalize the observed magnetic properties. ${ }^{74}$ The used methodology, namely ZORA/B3LYP computations combined with the Broken Symmetry (BS) aproach ${ }^{75-78}$ had already been successfully applied in the case of actinide-containing systems. ${ }^{79-81}$

In this work, we investigate the electronic structure and the nature of the magnetic interactions of the bimetallic $\left[\mathrm{UO}_{2}(\mathrm{dbm})_{2} \mathrm{~K}(18 \mathrm{C} 6)\right]_{2}(\mathrm{dbm}=$ dibenzoylmethanate $)$ and of the trimetallic $\left[\mathrm{UO}_{2}(\mathrm{~L})\right]_{3}(\mathrm{~L}=2$ (4-Tolyl)-1,3-bis(quinolyl)malondiiminate) complexes exhibiting diamondshape $\mathrm{U}_{2} \mathrm{O}_{2}$ and symmetrical triangular-shape $\mathrm{U}_{3} \mathrm{O}_{3}$ cores respectively, with $5 \mathrm{f}^{1}-5 \mathrm{f}^{1}$ and $5 \mathrm{f}^{1}-5 \mathrm{f}^{1}-$ $5 \mathrm{f}^{1}$ configurations, synthesized and characterized by M. Mazzanti and co-workers. ${ }^{63,72}$ These systems as illustrated in scheme 1 , differ from those synthesized by K. Mayer et al. ${ }^{71}$ as their $\mathrm{X}$-ray structures exhibit $\mathrm{UO}_{2}{ }^{+} \cdots \mathrm{UO}_{2}{ }^{+} \mathrm{CCI}$ rather than oxo bridges.

The dependence of exchange coupling on structural parameters, namely the M-O, M---M distances and the MOM angle in the cases of oxo-bridged transition metal systems, ${ }^{82-85}$ has been largely investigated, but there have been very few magnetostructural studies reporting influence of structural changes on the exchange coupling in actinide complexes. ${ }^{86-89}$ Thus, the influence of the environment and of distortions of the $\mathrm{U}_{\mathrm{x}} \mathrm{O}_{\mathrm{x}}(\mathrm{x}=2,3)$ cores on the magnetic properties will be explored by considering small models i.e. $\left.\left[\mathrm{UO}_{2} \text { (methanate }\right)_{2} \mathrm{~K}\right]_{2}$ and $\left[\mathrm{UO}_{2}(\mathrm{~L})\right]_{3}(\mathrm{~L}=$ bis $(\mathrm{Me})$ malondiiminate $)$ systems. Such investigations could reveal dramatic effects of small distortions of the core geometry on the strength and nature of the magnetic coupling.

\section{- Results and discussion}

\section{Computational Details:}

The calculations were performed using the Amsterdam Density Functional (ADF) package, 2016.04 release program version. ${ }^{90-92}$ Relativistic corrections have being introduced via the Zeroth Order Regular Approximation (ZORA) $)^{93-96}$ accounting for scalar relativistic effects. The DFT geometry optimizations of the High Spin (HS) states, which have been carried out using the BP86 exchange and correlation functionals of Becke and Perdew (BP86 functional), ${ }^{97-99}$ 
employed triple- $\zeta$-plus polarization (TZP) all-electron Slater type orbitals (STO) basis sets. The integration parameter that drives the integral accuracy computation has been put equal to 8.0. Our previous works, ${ }^{74,79,80,84,100,101}$ and several theoretical studies ${ }^{102-106}$ have shown that such a ZORA/BP86/TZP procedure reproduces the experimental geometries of $f$-element compounds with a satisfying accuracy. The computation of the $J$ exchange coupling constant has been done using the standard B3LYP hybrid functional. ${ }^{107,108}$ The B3LYP HS energies were obtained performing a single point calculation using the BP86 optimized geometries. The Broken Symmetry (BS) states were computed from the MOs of the HS structures as starting guesses according to the spin-flip recipe available in the ADF program. ${ }^{90}$ Comparative computations using the X-ray geometries of the complexes were also carried out. In fact, in the latter case the hydrogen atoms coordinates have been optimized since X-ray measurements are generally not able to locate precisely their positions.

In the framework of the BS approach ${ }^{75-78}$ the $J$ constant is deduced from the energy difference between the HS and BS states according to the Heisenberg-Dirac-vanVleck (HDvV) Hamiltonian ${ }^{109,110}$ which takes the form $\hat{\mathrm{H}}=-2 J_{12} \hat{\mathrm{S}}_{1} \cdot \hat{\mathrm{S}}_{2}$, in the case of two spin centers: a positive $J$ indicates ferromagnetic coupling and the negative sign an antiferromagnetic one. $J$ is computed using the Yamaguchi formula: ${ }^{111,112}$

$$
J_{12}=\left(\mathrm{E}_{\mathrm{BS}}-\mathrm{E}_{\mathrm{HS}}\right) /\left(\left\langle\mathrm{S}^{2}\right\rangle_{\mathrm{HS}}-\left\langle\mathrm{S}^{2}\right\rangle_{\mathrm{BS}}\right)
$$

In this formula $\left\langle\mathrm{S}^{2}\right\rangle_{\mathrm{HS}}$ and $\left\langle\mathrm{S}^{2}\right\rangle_{\mathrm{BS}}$ are respectively the mean values of the squared spin operator for the HS and BS states. In the case of multiple spin centers, a generalized Hamiltonian ${ }^{113,114}$ can be used namely $\hat{\mathrm{H}}=-\sum J_{\mathrm{ij}} \hat{\mathrm{S}}_{\mathrm{i}} \cdot \hat{\mathrm{S}}_{\mathrm{j}}$ leading in the case of the trinuclear symmetrical $\left[\mathrm{UO}_{2}(\mathrm{~L})\right]_{3}$ complex, to a single $J$ value equal to $\left(\mathrm{E}_{\mathrm{BS}}-\mathrm{E}_{\mathrm{HS}}\right) / 2$, since $J_{12}=J_{13}=J_{23}=J$.

Molecular structure drawings spin densities and molecular orbital (MO) plots were generated using the ADF-GUI auxiliary program. ${ }^{90}$

\section{DFT geometry optimizations:}

First, we focused on the dinuclear $\mathrm{U}_{2} \mathrm{O}_{2}{ }^{61}$ and trinuclear $\mathrm{U}_{3} \mathrm{O}_{3}$ uranyl(V) complexes. ${ }^{72}$ The solid state crystal structure of the dinuclear complex shows the presence of two $\mathrm{K}(18 \mathrm{C} 6)^{+}$cations bound to each uranyl(V) oxygen. The structure of the trinuclear complex contains three uranyl moieties coordinated to each other to form an equilateral triangle. The DFT optimized molecular structures of the two complexes are displayed on Figure 1. 

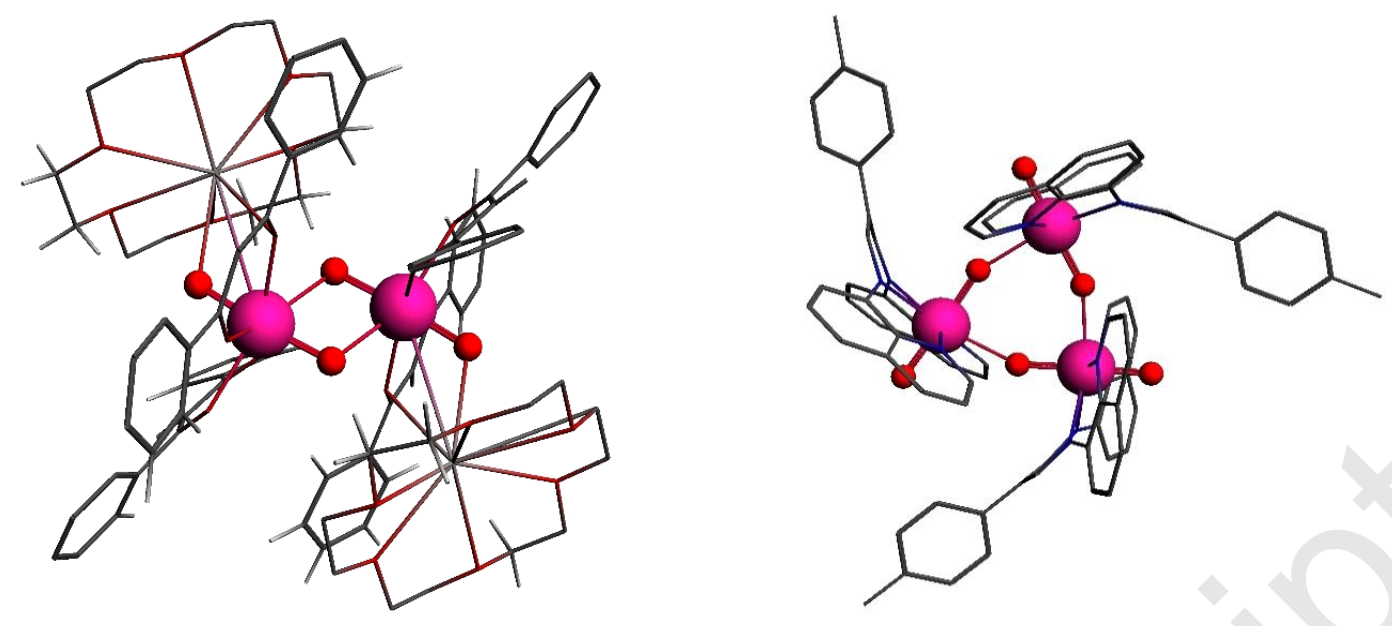

Figure 1: Optimized molecular structures of $\left[\mathrm{UO}_{2}(\mathrm{dbm})_{2} \mathrm{~K}(18 \mathrm{C} 6)\right]_{2}$ (left) and $\left[\mathrm{UO}_{2}(\mathrm{~L})\right]_{3}$ ( $\mathrm{L}=2$ (4-Tolyl)-1,3-bis(quinolyl)malondiiminate) (right). Sticks used to depict $\mathrm{C}, \mathrm{N}$ and $\mathrm{K}$ atoms; $\mathrm{H}$ atoms have been omitted for clarity. Pink and red colors respectively for uranium and oxygen atoms.

Two possible electron configurations of the uranium-centered $f$-electrons were considered for each complex, the $f^{\alpha} f^{\alpha}$ high-spin (HS) triplet and the $f^{\alpha} f^{\beta}$ Broken Symmetry (BS) states for $\left[\mathrm{UO}_{2}(\mathrm{dbm})_{2} \mathrm{~K}(18 \mathrm{C} 6)\right]_{2}$, and $f^{\alpha} f^{a} f^{\alpha} \mathrm{HS}$ quartet and the $f^{\beta} f^{\alpha} f^{\alpha} \mathrm{BS}$ doublet states for $\mathrm{U}_{3} \mathrm{O}_{3}$ system. Note that in the latter case, we checked (vide infra) that other possible BS spin configurations, i.e. $f^{\alpha} f^{\beta} f^{a}$ or $f^{\beta} f^{\beta} f^{\alpha}$ led to the same BS energy, as expected considering the highly symmetrical structure of $\left[\mathrm{UO}_{2}(\mathrm{~L})\right]_{3}$.

In Tables 1 and 2 are given relevant optimized bond distances and angles of the $\mathrm{U}_{2} \mathrm{O}_{2}$ and $\mathrm{U}_{3} \mathrm{O}_{3}$ complexes, in their triplet and quartet states, respectively. Available X-ray structural parameters ${ }^{63,72}$ are also given in these tables. Important geometrical parameters of the $\mathrm{U}_{2} \mathrm{O}_{2}$ and $\mathrm{U}_{3} \mathrm{O}_{3}$ cores are displayed on Figure 2 .
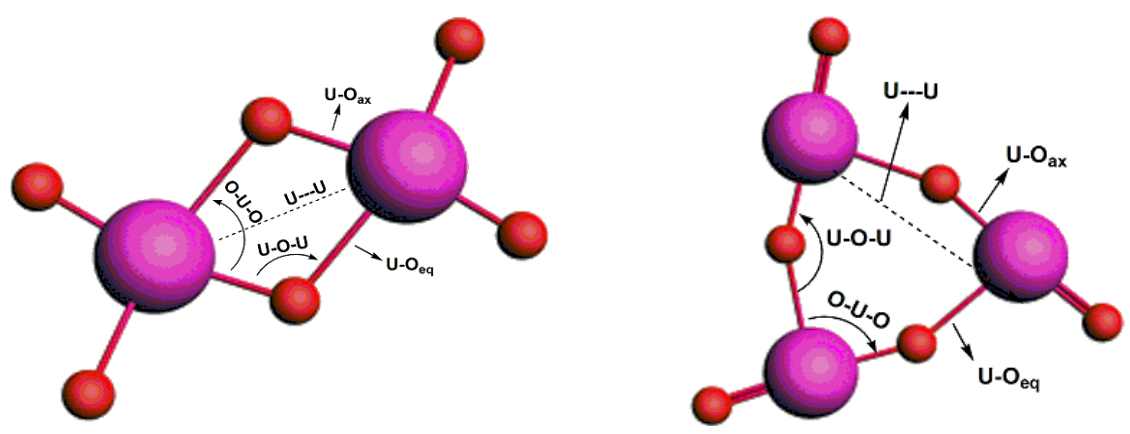
Figure 2: geometrical parameters of the $\mathrm{U}_{2} \mathrm{O}_{2}$ and $\mathrm{U}_{3} \mathrm{O}_{3}$ cores (see Figure 1 for atoms color code)

As can be seen in Tables 1 and 2, there is a good overall agreement between the DFT optimized distances and the X-ray structures. The difference between the long and short oxo-bridged $\mathrm{U}-\mathrm{O}$ distances in the $\mathrm{U}_{2} \mathrm{O}_{2}$ and $\mathrm{U}_{3} \mathrm{O}_{3}$ cores is attributed to their uranium-oxo single and double bond characters. Note that the difference between the short and long $\mathrm{U}-\mathrm{O}$ distances is more important than that observed in the $\mathrm{U}_{2} \mathrm{O}_{2}$ dioxo complexes of $\mathrm{K}$. Meyer and co-workers. ${ }^{71}$ Indeed, in the latter species, these bond lengths are equal to 2.036 and $2.212 \AA$ (X-ray data) giving a difference of $0.176 \AA$, whereas the corresponding values ${ }^{61}$ for the considered $\mathrm{U}_{2} \mathrm{O}_{2}$ complex are 1.941 and $2.384 \AA$, so that the difference between the bond lengths equal to $0.443 \AA$ is much higher. This is in agreement with the presence of a uranyl group only slightly elongated by the CCI interaction in the $\mathrm{U}_{2} \mathrm{O}_{2}$ complex.

Table 1: Optimized ZORA/BP86/TZP bond distances $(\AA)$ and angles $\left({ }^{\circ}\right)$ of $\left[\mathrm{UO}_{2}(\mathrm{dbm})_{2} \mathrm{~K}(18 \mathrm{C} 6)\right]_{2}$ and corresponding X-ray values.

\begin{tabular}{ccc}
\hline$\left[\mathrm{UO}_{2}(\mathrm{dbm})_{2} \mathrm{~K}(18 \mathrm{C} 6)\right]_{2}$ & $\langle\mathrm{X} \text {-Ray }\rangle^{63}$ & $\langle\mathrm{DFT}\rangle$ \\
\hline $\mathrm{U}-\mathrm{O}_{\mathrm{ax}}$ & $1.941(4)$ & 1.929 \\
$\mathrm{U}-\mathrm{O}_{\mathrm{eq}}$ & $2.384(4)$ & 2.462 \\
$\mathrm{U}-\mathrm{O}$ & $1.850(4)$ & 1.858 \\
$\mathrm{U}---\mathrm{U}$ & 3.462 & 3.553 \\
OUO & 74.1 & 72.6 \\
$\mathrm{UOU}$ & 105.9 & 107.4 \\
\hline
\end{tabular}

Table 2: Optimized ZORA/BP86/TZP bond distances $(\AA)$ and angles $\left(^{\circ}\right)$ of $\left[\mathrm{UO}_{2}(\mathrm{~L})\right]_{3}$ and corresponding X-ray values.

\begin{tabular}{ccc}
\hline$\left[\mathrm{UO}_{2}(\mathrm{~L})\right]_{3}$ & $\langle\mathrm{X}-\mathrm{Ray}\rangle^{72}$ & $\langle\mathrm{DFT}\rangle$ \\
\hline $\mathrm{U}-\mathrm{O}_{\mathrm{ax}}$ & $1.842(10)$ & 1.920 \\
$\mathrm{U}-\mathrm{O}_{\mathrm{eq}}$ & $2.374(8)$ & 2.410 \\
$\mathrm{U}-\mathrm{O}$ & $1.905(10)$ & 1.920 \\
$\mathrm{U}---\mathrm{U}$ & $4.19(2)$ & 4.23 \\
\hline
\end{tabular}




\begin{tabular}{ccc}
\hline OUO & $84.2(3)$ & 84.8 \\
UOU & $156.1(11)$ & 155.0 \\
\hline
\end{tabular}

For the $\left[\mathrm{UO}_{2}(\mathrm{dbm})_{2} \mathrm{~K}(18 \mathrm{C} 6)\right]_{2}$ complex, the optimized $\mathrm{U}---\mathrm{U}$ distance is slightly longer than the experimental one (3.553 vs. $3.462 \AA$ ). In the trioxo $\left[\mathrm{UO}_{2}(\mathrm{~L})\right]_{3}$ complex, the mean U---U distance (4.23 DFT vs. X-ray $4.19 \AA$ ), is shorter than that found of the previously reported tetrameric CCI complexes $\left[\mathrm{UO}_{2}(\mathrm{dbm})_{2}\right]_{4}\left[\mathrm{~K}_{4}\left(\mathrm{CH}_{3} \mathrm{CN}\right)_{4}\right],(4.315(5) \AA)^{61}$ and $\left[\left\{\mathrm{UO}_{2}(\text { salen })\right]_{4}\right\}\left(\mu_{8^{-}}\right.$ $\left.\left.\mathrm{K})_{2}\right]\left[\{\mathrm{K}(18 \mathrm{C} 6) \mathrm{Py})_{2}\right\}\right](4.31(3) \AA$ ) where the four uranyl(V) groups interact in a the T-shaped fashion (Scheme 1). ${ }^{72}$

Since the full geometry optimization that we carried out led to small deviations between the Xray and the fully optimized structures (vide supra) which could be of importance for the magnetic property under consideration, we also considered for the actual complexes, structures for which the $\mathrm{X}$-ray $\mathrm{U}_{\mathrm{x}} \mathrm{O}_{\mathrm{x}}$ core geometries has been retained. Indeed, it was observed in the case of the dihydroxo dichromium(III) system, ${ }^{84}$ that a slight distortion of the $\mathrm{Cr}_{2}(\mu-\mathrm{OH})_{2}$ magnetic core, replacing the DFT geometry by the X-ray one led to a better agreement between the computed and the observed magnetic coupling constant.

Furthermore, to gain deeper insight into the effect of small structural changes on the electronic and magnetic behaviour of the $\mathrm{U}_{\mathrm{x}} \mathrm{O}_{\mathrm{x}}$ cores, various small models preserving the $\mathrm{U}_{2} \mathrm{O}_{2}$ and $\mathrm{U}_{3} \mathrm{O}_{3}$ $\mathrm{X}$-ray core geometries have been considered. These models i.e. $\left[\mathrm{UO}_{2} \text { (methanate) }{ }_{2} \mathrm{~K}\right]_{2}$ and $\left[\mathrm{UO}_{2}(\mathrm{~L})\right]_{3}(\mathrm{~L}=$ bis $(\mathrm{Me})$ malondiiminate $)$ extracted from the crystal structures, were in the first step optimized with fixed core. Their optimized molecular structures are depicted on Figure 3. The $\mathrm{U}_{\mathrm{x}} \mathrm{O}_{\mathrm{x}}$ core was kept strictly planar as observed in the experimental crystallographic structure.

On the second step, small distortions of the $\mathrm{U}_{\mathrm{x}} \mathrm{O}_{\mathrm{x}}$ core geometry of the models were considered by varying the UOU and OUO bond angles (see Figure 2$)$ and keeping the $\mathrm{U}-\mathrm{O}\left(\mathrm{U}-\mathrm{O}_{\mathrm{ax}} / \mathrm{U}-\mathrm{O}_{\mathrm{eq}}\right)$

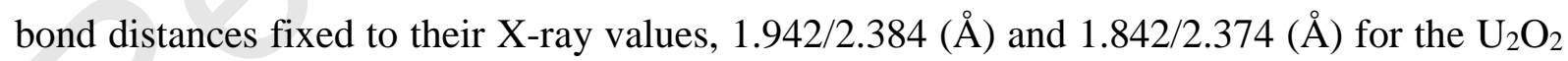
and $\mathrm{U}_{3} \mathrm{O}_{3}$ species, respectively. In Table 3 , after geometry optimization, the different modified structural parameters, i.e. the U---U distance and the UOU and OUO angles of the $\mathrm{U}_{\mathrm{x}} \mathrm{O}_{\mathrm{x}}$ modified core (mc) and the corresponding relative total bonding energy (TBE) computed at the ZORA/B3LYP/TZP level, are given for the HS state of the dioxo $\left[\mathrm{UO}_{2} \text { (methanate }{ }_{2} \mathrm{~K}\right]_{2}$ and trioxo $\left[\mathrm{UO}_{2}(\mathrm{~L})\right]_{3}(\mathrm{~L}=$ bis$(\mathrm{Me})$ malondiiminate) models; X-ray structural parameters are also given in this table. Several geometrical models have been considered, namely mc1-mc 7 for the $\mathrm{U}_{2} \mathrm{O}_{2}$ species and mc8-mc12 for the $\mathrm{U}_{3} \mathrm{O}_{3}$ one. 

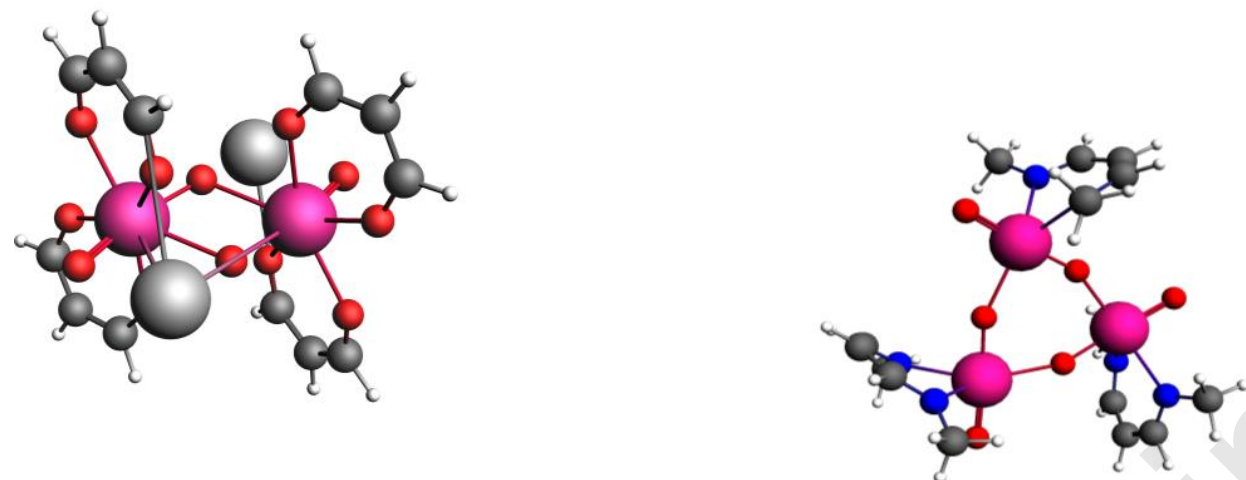

Figure 3: ZORA/BP86/TZP optimized molecular structures of $\left[\mathrm{UO}_{2} \text { (methanate) }{ }_{2} \mathrm{~K}\right]_{2}$ (left) and $\left[\mathrm{UO}_{2}(\mathrm{~L})\right]_{3}(\mathrm{~L}=$ bis $(\mathrm{Me})$ malondiiminate) models (right) with modified core geometries. Pink, red, blue, grey, deep grey and white colors respectively for uranium, oxygen, nitrogen, potassium, carbon and $\mathrm{H}$ atoms.

Table 3: Relevant ZORA/B3LYP/TZP geometric parameters, U---U intermetallic distance $(\AA)$ and UOU and OUO bond angles $\left(^{\circ}\right)$ of the $\mathrm{U}_{\mathrm{x}} \mathrm{O}_{\mathrm{x}}$ modified core (mc) models in their HS state and available $\mathrm{X}$-ray values. $\Delta \mathrm{E}$ is the relative energy between the different forms.

\begin{tabular}{rccccc}
\hline Models & $\mathbf{U}--\mathbf{U}$ & $\langle\mathbf{U}-\mathbf{O}-\mathbf{U}\rangle$ & $\langle\mathbf{O}-\mathbf{U}-\mathbf{O}\rangle$ & $\begin{array}{c}\mathbf{T B E} \\
(\mathbf{e V})\end{array}$ & $\begin{array}{c}\Delta \mathbf{E} \\
(\mathbf{k c a l} / \mathbf{m o l})\end{array}$ \\
\hline mc1 & 3.275 & 97.9 & 82.1 & -312.7162 & 0.26 \\
mc2 & 3.418 & 103.9 & 76.1 & -312.9620 & 0.01 \\
(X-ray) mc3 & $\mathbf{3 . 4 6 2}$ & $\mathbf{1 0 5 . 9}$ & $\mathbf{7 4 . 1}$ & $\mathbf{- 3 1 2 . 9 7 9 7}$ & 0.0 \\
mc4 & 3.572 & 110.9 & 69.1 & -312.8688 & 0.11 \\
mc5 & 3.634 & 113.9 & 66.1 & -312.6918 & 0.28 \\
mc6 & 3.654 & 114.9 & 65.1 & -312.4360 & 0.54 \\
mc7 & 3.694 & 116.9 & 63.1 & -312.4250 & 0.55 \\
mc8 & 4.168 & 153.5 & 86.5 & -420.2289 & 0.59 \\
mc9 & 4.177 & 154.5 & 85.5 & -420.2661 & 0.56 \\
mc10 & $\mathbf{4 . 1 9 2}$ & $\mathbf{1 5 7 . 1}$ & $\mathbf{8 4 . 3}$ & -420.8265 & 0.0 \\
mc11 & 4.207 & 158.5 & 81.5 & -420.2583 & 0.56 \\
mc12 & 4.226 & 161.0 & 78.5 & -420.7972 & 0.03 \\
\hline
\end{tabular}


As it can be seen in Table 3, it is worth noting that deviations of the UOU or OUO bond angles

$\left(^{\circ}\right)$ from the $\mathrm{X}$-ray $\mathrm{U}_{2} \mathrm{O}_{2}$ data $\left(105.9^{\circ}\right.$ and $74.1^{\circ}$ respectively) affect only very slightly the stability of the different models (less than $c a .0 .3 \mathrm{kcal} / \mathrm{mol}$ ) relatively to the model with fixed $\mathrm{X}$-ray $\mathrm{U}_{2} \mathrm{O}_{2}$ core (mc3) which is the most stable. It is noteworthy that in the dioxo $\mathrm{U}_{2} \mathrm{O}_{2}$ case, the increase or decrease of the bond angles up to $8^{\circ}$, leads to the U---U distance variation by ca. $0.2 \AA$ only.

Similarly, in the trioxo $\mathrm{U}_{3} \mathrm{O}_{3}$ case, it can be seen that the considered distortions of the core models which lead to an average U---U distance variation less than ca. $0.02 \AA$, affect slightly the relative stability of the different structures compared to the most stable mc10 model in which the UOU and OUO bond angles are fixed equal to the X-ray values i.e., 157.1 and 84.3 $\left.{ }^{\circ}\right)$ respectively.

\section{Electronic structure analysis:}

Bond order analysis. The Natural Population Analysis (NPA) as well as Mayer ${ }^{115}$ and Nalewajski-Mrozek (NM) ${ }^{116,117}$ bond orders have been calculated for the $\mathrm{U}_{2} \mathrm{O}_{2}$ dioxo and $\mathrm{U}_{3} \mathrm{O}_{3}$ trioxo mc3 and mc10 models with fixed X-ray core geometry, respectively. The results are reported in Table 4.

Table 4: ZORA/BP86/TZP Mayer and NM average bond orders of the dioxo and trioxo $\mathrm{U}_{\mathrm{x}} \mathrm{O}_{\mathrm{x}}$ models, in their triplet $(\mathrm{T})$ and quartet $(\mathrm{Q})$ states, respectively.

\begin{tabular}{ccccccc}
\hline $\begin{array}{c}(\mathrm{X}-\mathrm{ray}) \\
\mathrm{U}_{\mathrm{x}} \mathrm{O}_{\mathrm{x}}\end{array}$ & \multicolumn{3}{c}{$\mathrm{U}-\mathrm{O}_{\mathrm{ax}} / \mathrm{U}-\mathrm{O}_{\mathrm{eq}}$} & \multicolumn{3}{c}{$\mathrm{U}---\mathrm{U}$} \\
models & $d(\AA)$ & Mayer & $\mathrm{NM}$ & $d(\AA)$ & Mayer & $\mathrm{NM}$ \\
\hline $\mathrm{U}_{2} \mathrm{O}_{2} \mathbf{m c 3}$ & $1.941 / 2.384$ & $1.289 / 0.375$ & $2.303 / 1.076$ & 3.462 & 0.047 & -0.828 \\
$\mathrm{U}_{3} \mathrm{O}_{3} \mathbf{m c 1 0}$ & $1.842 / 2.374$ & $1.395 / 0.413$ & $2.398 / 1.112$ & 4.192 & 0.056 & -0.996
\end{tabular}

As expected, the $\mathrm{U}_{\mathrm{x}} \mathrm{O}_{\mathrm{x}}$ cores exhibit formally both single and double $\mathrm{U}-\mathrm{O}$ bond characters. The NM approach, which accounts for ionic and covalent contributions, gives greater metal-ligand bond orders (up to two times) than Mayer's ones. Concerning the dioxo $\mathrm{U}_{2} \mathrm{O}_{2}$ mc3 model with fixed X-ray core, the difference between axial and equatorial bond lengths, $\mathrm{U}-\mathrm{O}_{\mathrm{ax}}$ and $\mathrm{U}-\mathrm{O}_{\mathrm{eq}}$ respectively, is well traduced by their $\mathrm{U}-\mathrm{O}_{\mathrm{ax}} / \mathrm{U}-\mathrm{O}_{\mathrm{eq}}$ double and single bond characters. This trend is well confirmed by their Mayer and NM bond orders, as exemplified for the dioxo model mc3 i.e. 1.289 vs. 0.375 for Mayer and 2.303 vs. 1.076 for NM, respectively. Similarly, for the 
$\mathrm{U}_{3} \mathrm{O}_{3}$ model with X-ray core namely mc10, the double bond character of the $\mathrm{U}-\mathrm{O}_{\mathrm{ax}}$ axial coordination, is well reproduced by the Mayer and NM indices i.e. 1.395 vs. 2.398, respectively, whereas the $\mathrm{U}-\mathrm{O}_{\mathrm{eq}}$ equatorial single bonds exhibit the following Mayer and NM orders of 0.413 vs. 1.112, respectively.

As reported by previous works on related dioxo $U(\mu-\mathrm{O})_{2} \mathrm{U}$ systems, ${ }^{63,64,70,71,118-121}$ short $\mathrm{U}---\mathrm{U}$ distance in the $\left[\mathrm{UO}_{2}(\mathrm{dbm})_{2} \mathrm{~K}(18 \mathrm{C} 6)\right]_{2}$ complex could permit metal-metal electronic communication thus favouring magnetic exchange coupling between the $\mathrm{U}^{\mathrm{V}}$ spin centers. Furthermore, as reported recently by M. J. Monreal et al., ${ }^{121}$ magnetic coupling may occur through metal-metal orbital overlap in the mixed-valence linear trinuclear $\mathrm{Fe}^{\mathrm{II}} \mathrm{U}^{\mathrm{IV}} \mathrm{Fe}^{\mathrm{III}}$ cluster $\left[\mathrm{UFe}_{2}\left(\mathrm{C}_{5} \mathrm{H}_{4} \mathrm{NSi}-\left({ }^{\mathrm{t}} \mathrm{Bu}\right) \mathrm{Me}_{2}\right)_{4}\right]^{+}$. In our case, the U---U separation within the mc3 dioxo model equal to $3.462 \AA$, is significantly shorter than twice the covalent radius of the uranium atom (3.920 ̊),${ }^{64}$ but much larger than twice the $\mathrm{U}(\mathrm{V})$ ionic radius equal to ca. $1.80 \AA$ A. Similarly, the U---U distance in the trioxo mc10 model, equal to 4.19(1) $\AA$ X-ray data, is in the same range as the mean U---U distance found in the T-shaped cores of the salen tetramer decorated with sodium cations $\left\{\left[\mathrm{UO}_{2}(\text { salen })\right]_{4}\left[\mu_{8}-\mathrm{Na}\right]_{2}\right\} .2\left[\mathrm{Na}(18 \mathrm{C} 6)(\mathrm{py})_{2}\right]\left(4.20(5) \AA{ }^{72}\right.$ However, these U--$\mathrm{U}$ distances, are significantly longer than those reported for the asymmetric diamond-shaped $\left(\mathrm{UO}_{2}\right)_{2}$ cores found in the $\left[\mathrm{UO}_{2}(\mathrm{dbm})_{2} \mathrm{~K}(18 \mathrm{C} 6)\right]_{2}{ }^{63}$ dimers and in the $\left[\mathrm{UO}_{2} \text { (pacman }\right)_{2} \mathrm{Sm}(\text { py) }]_{2}{ }^{122}$ complexes $(\mathrm{U}---\mathrm{U}=3.462 \AA$ for the $\mathrm{dbm}$ complex and $3.471 \AA$ for the pacman complex). Although a small covalent interaction between the uranium atoms could be suggested by the calculated Mayer bond orders of $c a .0 .047$ in the dioxo models and $c a$. 0.056 in trioxo models (Table 4), the NM bond orders, which include ionic contribution to the bonding, are significantly negative and equal to $c a$. -0.828 and $c a$. -0.996 in $\mathrm{U}_{2} \mathrm{O}_{2}$ and $\mathrm{U}_{3} \mathrm{O}_{3}$ $\mathrm{X}$-ray mc3 and mc10 models respectively, indicating unfavourable anti-bonding interactions. This confirms the preferred tendency of uranium ions to bind ligands, rather than to form a direct $\mathrm{U}^{\mathrm{V}}---\mathrm{U}^{\mathrm{V}}$ bonding.

The bonding analysis has been confirmed using NPA ${ }^{123}$ and the Quantum Theory of Atoms in Molecules (QTAIM) ${ }^{124}$ descriptors (see Supplementary Information) reminding that for $f$ element complexes, the latter approach was used to probe the covalence and gave results in good agreement with experimental trends. ${ }^{125-129}$

Molecular Orbital Analysis. The frontier MO diagrams of the HS and BS states of the $\left.\left[\mathrm{UO}_{2} \text { (methanate) }\right)_{2} \mathrm{~K}\right]_{2}(\mathbf{m c 3})$ and trioxo $\left[\mathrm{UO}_{2}(\mathrm{~L})\right]_{3}(\mathrm{~L}=$ bis $(\mathrm{Me})$ malondiiminate) (mc10) models are given on Figures 4, 5, 6 and S1 (Supplementary Information) respectively. In these diagrams $\%(6 \mathrm{~d} / 5 \mathrm{f} / \mathrm{U} /$ Ligand $)$ represents respectively the percentage weight of the $6 \mathrm{~d} / 5 \mathrm{f}$ metal orbitals, 
the uranium atoms and of the ligands within the displayed frontier MOs. The highest occupied MOs of the dioxo mc3 and trioxo mc10 models, in their respective HS triplet and quartet states (Figures 4 and 6) are the two degenerate $\alpha$ singly occupied SOMO (202A) and SOMO-1 (201A) of $\mathbf{m c 3}$ with their energy equal to $-4.593 \mathrm{eV}$ (Figure 4) and the three $\alpha$ singly occupied SOMO (87A"), SOMO-1 (86A") and SOMO-2 (85A") of mc10 which are also degenerate with energy $-5.336 \mathrm{eV}$ (Figure 6). These MOs exhibit mainly metallic $5 \mathrm{f}_{\mathrm{xyz}}$ orbital character with almost no contribution from the bridging uranyl oxo groups.

In the BS state of the mc3 model (Figure 5) the SOMOs are localized separately on the $\mathrm{U}^{\mathrm{V}}$ spin centers with also mainly a $5 \mathrm{f}_{\mathrm{xyz}}$ character. The most striking feature in the HS and BS MO diagrams of the dioxo mc3 model (Figures 4 and 5) is the existence of MO \#192A traducing the $\sigma$ U-oxo axial coordination within the $\mathrm{U}_{2} \mathrm{O}_{2}$ core and indicating that the equatorial coordination are deeper in energy, involving the contribution from both uranium $6 \mathrm{~d}$ and oxo $\mathrm{O}(2 \mathrm{p})$ orbitals. 


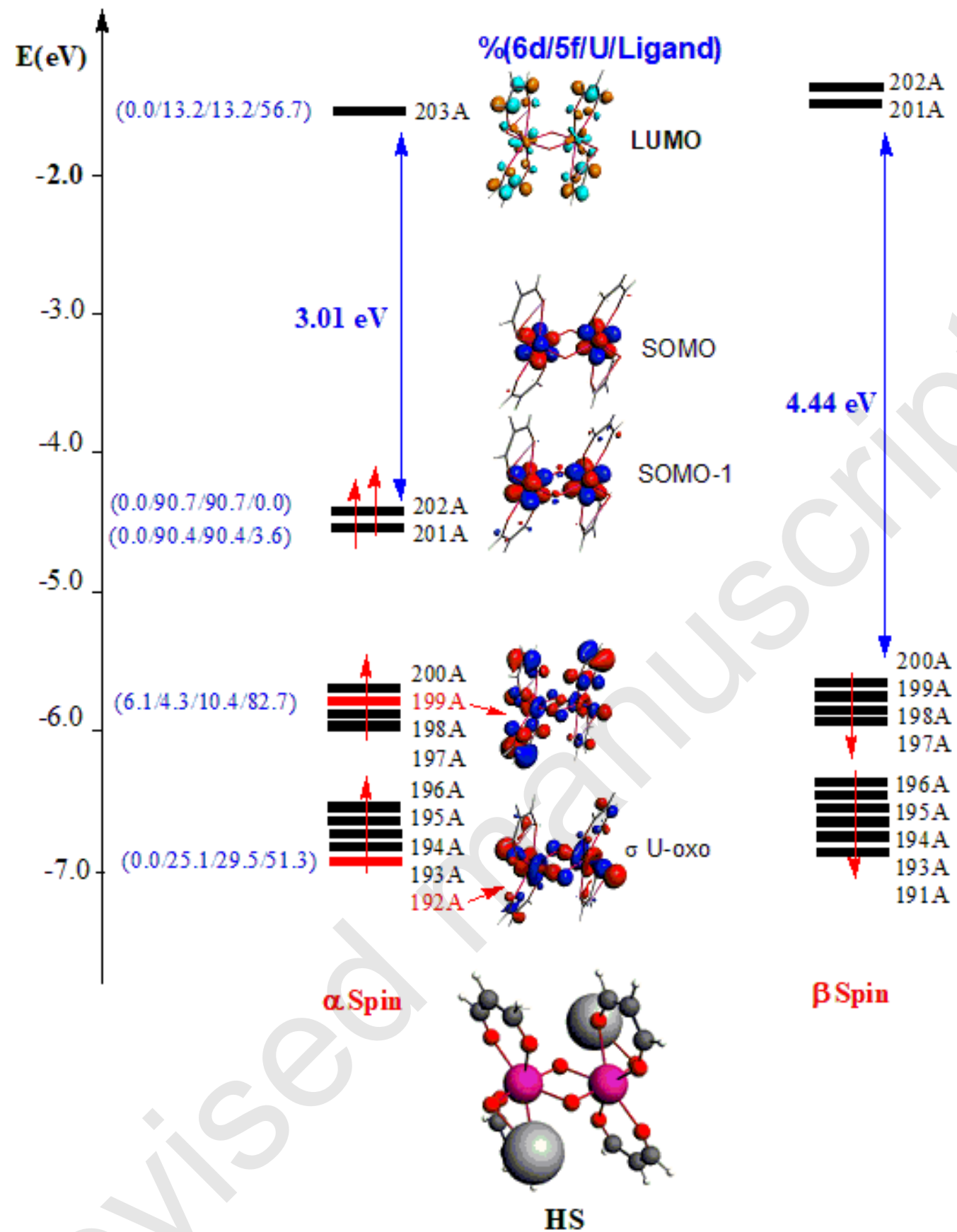

Figure 4: B3LYP Frontier MO diagram of the dioxo mc3 model in its HS (triplet) state. 


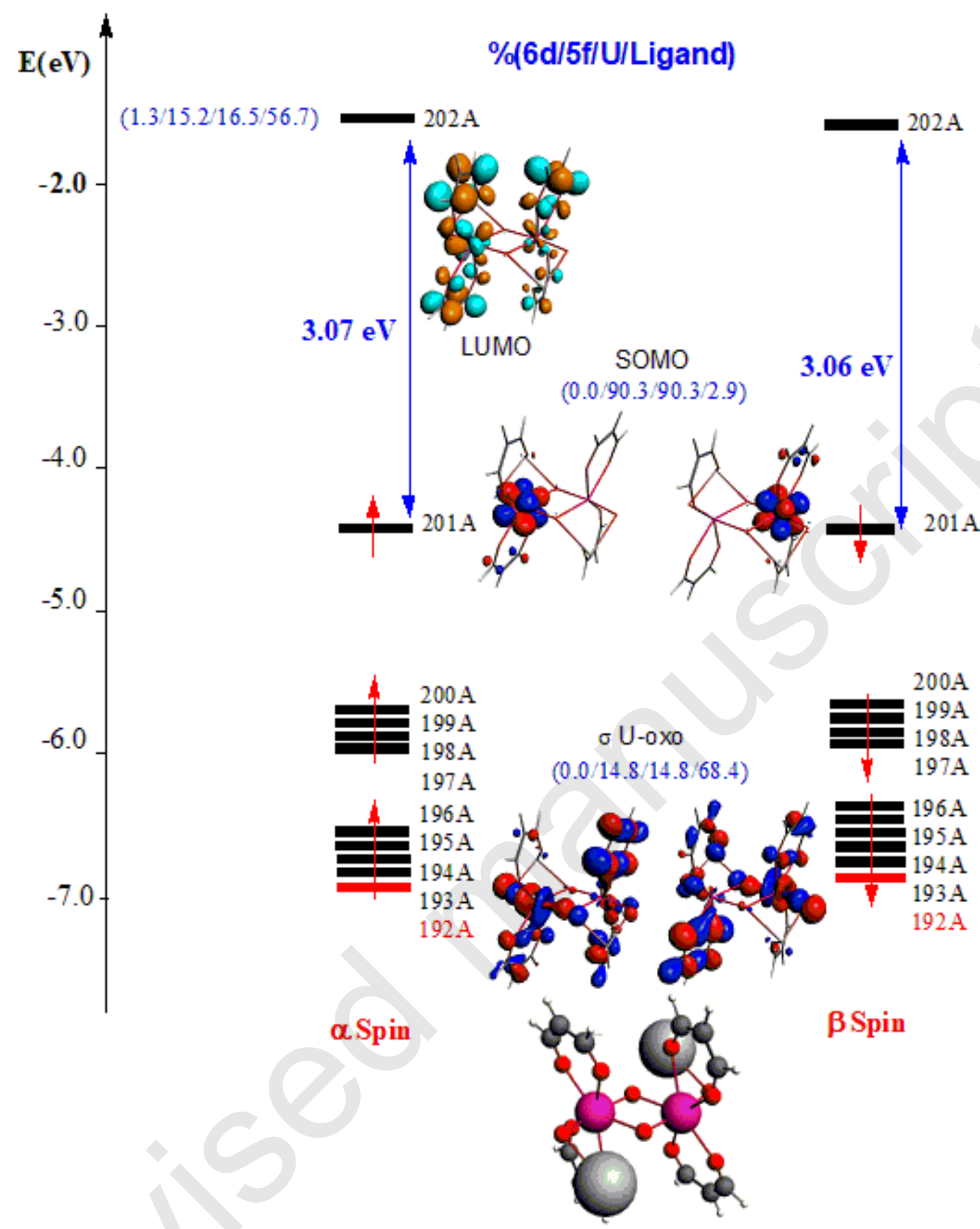

BS

Figure 5: B3LYP Frontier MO diagram of the dioxo mc3 model in its BS state.

Interestingly, the LUMOs of the dioxo mc3 complex, either in the HS or BS states, are not $5 f$ uranium orbitals, contrarily to that computed in the K. Meyer's U(V) bis- $\mu$-oxo complex ${ }^{71}$ so that a direct reduction of the $\left[\mathrm{UO}_{2}(\mathrm{dbm})_{2} \mathrm{~K}(18 \mathrm{C} 6)\right]_{2}$ complex is not expected to lead straightforwardly to a binuclear U(IV) species. This is in agreement with the observed difficulty to reduce uranyl(V) complexes to uranium(IV) species. 
In the case of the $\left[\mathrm{UO}_{2}(\mathrm{~L})\right]_{3}$ complex, the HS (quartet) state electronic structure can be described by the mc10 model which exhibits three highest $\alpha$ singly occupied SOMOs \#87A", 86A" A and

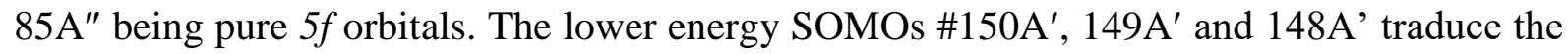
$\sigma$ and $\pi$ U-oxo coordination sustaining the triangular and planar $\mathrm{U}_{3} \mathrm{O}_{3}$ core structure. The corresponding BS SOMOs in the mc10 congener (Figure S1), noted $\alpha-\left(86 \mathrm{~A}^{\prime \prime}, 85 \mathrm{~A}^{\prime \prime}\right)$ and $\beta$ $\left(85 \mathrm{~A}^{\prime \prime}\right)$ are essentially $5 f$ orbitals of the three uranium(V) atoms with no contribution from the bridging trioxo ligand, except for the $\beta-\left(85 \mathrm{~A}^{\prime \prime}\right)$ component which exhibits a very weak contribution of the ligand (1.6\%). Furthermore, the lower $\pi$ SOMO \#148A' exhibiting contribution of the oxo groups, traduces the U-oxo coordination. It is likely that such SOMOs, appearing in both dioxo and trioxo models, are acting to favour the metal-metal electronic and magnetic exchange interactions. 


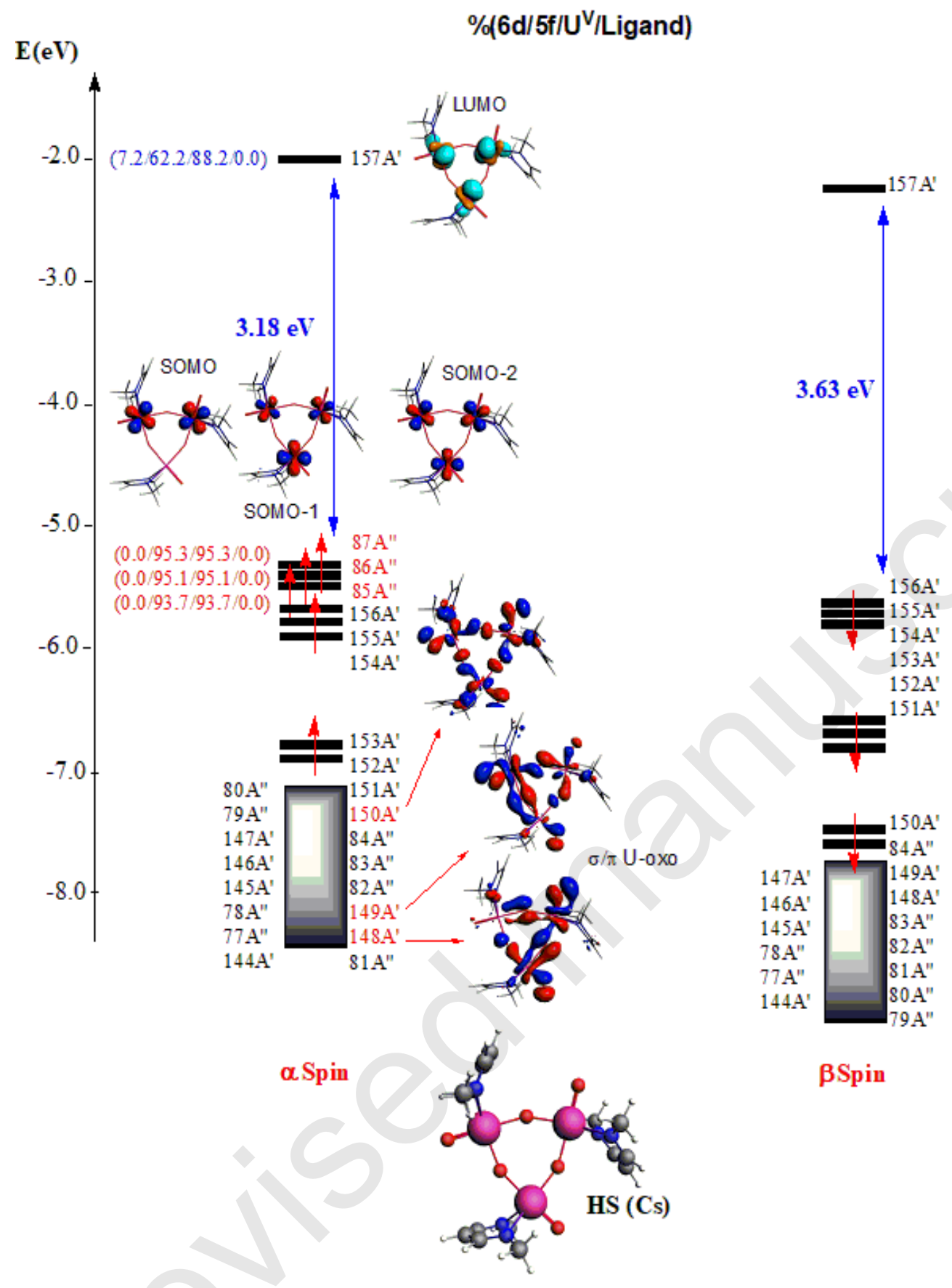

Figure 6: B3LYP Frontier MO diagram of the trioxo mc10 model in its HS (quartet) state.

In Table 5, are reported the computed B3LYP Total Bonding Energy TBE(eV), $\Delta \mathrm{E}=\mathrm{E}_{\mathrm{BS}}-\mathrm{E}_{\mathrm{HS}}$ energy differences, the mean values $\left\langle\mathrm{S}^{2}\right\rangle$ through which spin contamination of the HS state can be estimated, as well as the computed exchange coupling constants $J$ for the fully optimized $\left[\mathrm{UO}_{2}(\mathrm{dbm})_{2} \mathrm{~K}(18 \mathrm{C} 6)\right]_{2}$ and $\left[\mathrm{UO}_{2}(\mathrm{~L})\right]_{3}$ complexes and their corresponding optimized structures with fixed $\mathrm{U}_{\mathrm{x}} \mathrm{O}_{\mathrm{x}} \mathrm{X}$-ray core geometry. 
Table 5: ZORA/B3LYP/TZP computed TBE(eV), $\Delta \mathrm{E}\left(\mathrm{eV} / \mathrm{cm}^{-1}\right),\left\langle\mathrm{S}^{2}\right\rangle$ values, and magnetic exchange coupling constant $J\left(\mathrm{~cm}^{-1}\right)$ for the $\left[\mathrm{UO}_{2}(\mathrm{dbm})_{2} \mathrm{~K}(18 \mathrm{C} 6)\right]_{2},\left[\mathrm{UO}_{2}(\mathrm{~L})\right]_{3}$ complexes.

\begin{tabular}{|c|c|c|c|c|c|c|}
\hline Complexes & $\begin{array}{l}\mathrm{TBE}_{\mathrm{HS}} \\
(\mathrm{eV})\end{array}$ & $\begin{array}{l}\mathrm{TBE}_{\mathrm{BS}} \\
(\mathrm{eV})\end{array}$ & $\Delta \mathrm{E}\left(\mathrm{cm}^{-1}\right)$ & $\left\langle\mathrm{S}^{2}\right\rangle_{\mathrm{HS}}$ & $\left\langle\mathrm{S}^{2}\right\rangle_{\mathrm{BS}}$ & $J\left(\mathrm{~cm}^{-1}\right)$ \\
\hline \multicolumn{7}{|c|}{ fully optimized structures } \\
\hline $\begin{array}{c}{\left[\mathrm{UO}_{2}(\mathrm{dbm})_{2} \mathrm{~K}(18 \mathrm{C} 6)\right]_{2}} \\
\left(5 \mathrm{f}^{1}-5 \mathrm{f}^{1}\right)\end{array}$ & -1455.770 & -1455.813 & -347.64 & 2.009 & 1.008 & -347.6 \\
\hline$\left[\mathrm{UO}_{2}(\mathrm{~L})\right]_{3}$ & -1320.719 & -1320.721 & -16.13 & 3.763 & 1.763 & -8.1 \\
\hline$\left(5 \mathrm{f}^{1}-5 \mathrm{f}^{1}-5 \mathrm{f}^{1}\right)$ & & & & & & \\
\hline \multicolumn{7}{|c|}{ optimized structures $\mathrm{U}_{\mathrm{x}} \mathrm{O}_{\mathrm{x}}$ with fixed $\mathrm{X}$-ray core geometry } \\
\hline $\mathrm{U}_{2} \mathrm{O}_{2}$ & -1467.937 & -1467.940 & -24.06 & 2.010 & 1.009 & -24.1 \\
\hline $\mathrm{U}_{3} \mathrm{O}_{3}$ & -1319.1482 & -1319.1500 & -14.44 & 3.763 & 1.764 & -7.2 \\
\hline
\end{tabular}

As expected, the results reported in Table 5 show that $\left\langle\mathrm{S}^{2}\right\rangle_{\mathrm{HS}}$ exhibits correct values close to 2 and 3.75 for the triplet $\mathrm{U}_{2} \mathrm{O}_{2}$ and quartet $\mathrm{U}_{3} \mathrm{O}_{3}$ states systems, thus indicating almost no spin contamination for the HS states. Furthermore, the computed $\left\langle\mathrm{S}^{2}\right\rangle$ in the BS states, is intermediate between the value for a real singlet $(S=0)$ and the triplet $S(S+1)=2$ value of the HS state for the $\left[\mathrm{UO}_{2}(\mathrm{dbm})_{2} \mathrm{~K}(18 \mathrm{C} 6)\right]_{2}$ complex and between the value for an exact doublet $\mathrm{S}(\mathrm{S}+1)=0.75$ and quartet $\mathrm{S}(\mathrm{S}+1)=3.75$ for the $\left[\mathrm{UO}_{2}(\mathrm{~L})\right]_{3}$ complex. The same behaviour is obtained for the two dioxo $\left.\left[\mathrm{UO}_{2} \text { (methanate }\right)_{2} \mathrm{~K}\right]_{2}$ and trioxo $\left[\mathrm{UO}_{2}(\mathrm{~L})\right]_{3} \quad(\mathrm{~L}=$ bis(Me)malondiiminate) models with fixed core geometry (vide infra). It is noteworthy that the difference between the computed $\left\langle\mathrm{S}^{2}\right\rangle_{\mathrm{HS}}$ and $\left\langle\mathrm{S}^{2}\right\rangle_{\mathrm{BS}}$ for the trioxo systems is exactly equal to 2 , as it must be regarding the symmetry of the magnetic core.

An important observation also from the results in Table 5 is that the $\mathrm{U}_{2} \mathrm{O}_{2}$ and $\mathrm{U}_{3} \mathrm{O}_{3}$ cores are predicted to display an AF coupling, in agreement with experimental findings. The used procedure i.e. ZORA/B3LYP computations in conjunction with the BS approach successfully predicts the actual AF character of such uranium(V) species leading also to a coupling constant equal to -8.1 and $-7.2 \mathrm{~cm}^{-1}$ for the full optimized $\mathrm{X}$-ray trioxo structure and with fixed $\mathrm{U}_{3} \mathrm{O}_{3}$ core geometry, respectively.

However, the obtained $J$ value for the actual binuclear $\left[\mathrm{UO}_{2}(\mathrm{dbm})_{2} \mathrm{~K}(18 \mathrm{C} 6)\right]_{2}$, when using a fully optimized geometry i.e. $-347.6 \mathrm{~cm}^{-1}$ is definitively too high, whereas when keeping fixed the X-ray geometry of the $\mathrm{U}_{2} \mathrm{O}_{2}$ core, the obtained value $\left(-24.1 \mathrm{~cm}^{-1}\right)$ is much more realistic. 
These results highlight the crucial role of the considered geometry of the magnetic core. Actually, small deviations of the magnetic core geometry could be responsible for a great variation of the magnetic coupling. Indeed, thanks to the reviewer, it can be seen in Table 1, that the BP86 optimized $\mathrm{U}-\mathrm{O}_{\mathrm{eq}}$ distance deviates noticeably from the X-ray one; this is probably responsible for the huge overestimation of the computed magnetic coupling constant for the dioxo complex. An optimal functional for geometry optimization of uranium complexes has been recently proposed. ${ }^{130 \text { ", }}$

The effect of the metal-ligand-metal bridge angle variation on the magnetic exchange interaction has been early studied in doubly bridged transition metal $\mathrm{M}(\mu-\mathrm{L}) \mathrm{M}$ dimers ${ }^{82,83}$ The low-spin and high-spin energy difference and the M-L orbital overlap are affected by this bond angle variation thus leading to a modification of the metal-metal magnetic interaction. ${ }^{82}$

However, to our knowledge, no systematic investigations of geometrical distortions effect on the exchange magnetic interaction have been provided in the diuranium cases. Hence, to get a deeper insight into the crucial role of the $\mathrm{U}_{\mathrm{x}} \mathrm{O}_{\mathrm{x}}$ core geometry on the magnetic exchange, the coupling constant $J$ was also computed for the different dioxo and trioxo mc(1-12) models which exhibit different structural distortions. Thus, the effect of modifying the core geometry on the coupling constant value was investigated considering the dioxo and trioxo models. One of the main goals of this study was to assess the relative stability of the systems towards core distortions through UOU and OUO bond angles variation (vide supra) and to provide more insights into the magneto-structural properties of bi- and trimetallic uranium(V) oxo-bridged complexes. In Table 6 , are reported the $\mathrm{TBE}(\mathrm{eV}), \Delta \mathrm{E}\left(\mathrm{cm}^{-1}\right)$ energy differences $\mathrm{TBE}_{\mathrm{BS}}-$ $\mathrm{TBE}_{\mathrm{HS}},\left\langle\mathrm{S}^{2}\right\rangle$ values, and exchange coupling $J\left(\mathrm{~cm}^{-1}\right)$ constant for the dioxo $\mathrm{mc}(1-7)$ and trioxo mc(8-12) models.

Table 6: ZORA/B3LYP/TZP computed TBE $(\mathrm{eV}), \Delta \mathrm{E}\left(\mathrm{cm}^{-1}\right),\left\langle\mathrm{S}^{2}\right\rangle$ values, and exchange coupling constant $J\left(\mathrm{~cm}^{-1}\right)$ for the different mc optimized models

\begin{tabular}{r|c|c|c|c|c|c}
\hline $\begin{array}{c}\text { mc models } \\
\mathrm{UOU}\left(^{\circ}\right)\end{array}$ & $\begin{array}{c}\mathrm{TBE}_{\mathrm{HS}} \\
(\mathrm{eV})\end{array}$ & $\begin{array}{c}\mathrm{TBE}_{\mathrm{BS}} \\
(\mathrm{eV})\end{array}$ & $\Delta \mathrm{E}\left(\mathrm{cm}^{-1}\right)$ & $\left\langle\mathrm{S}^{2}\right\rangle_{\mathrm{HS}}$ & $\left\langle\mathrm{S}^{2}\right\rangle_{\mathrm{BS}}$ & $J\left(\mathrm{~cm}^{-1}\right)$ \\
\hline \multicolumn{7}{|c}{$\mathrm{U}_{2} \mathrm{O}_{2}$ dioxo models } \\
\hline mc1: 97.9 & -312.716 & -312.723 & -56.45 & 2.008 & 1.002 & -56.1 \\
mc2: 103.9 & -312.962 & -312.966 & -32.26 & 2.008 & 1.004 & -31.2 \\
(X-ray) mc3 :105.9 & -312.9797 & -312.9825 & -22.43 & 2.010 & 1.008 & $\mathbf{- 2 2 . 4}$ \\
\hline
\end{tabular}




\begin{tabular}{r|c|c|c|c|c|c}
\hline mc4: 110.9 & -312.8688 & -312.8692 & -3.22 & 2.011 & 1.010 & -3.2 \\
mc5: 113.9 & -312.6918 & -312.6918 & 0.0 & 2.011 & 1.011 & 0.0 \\
mc6:114.9 & -312.4360 & -312.4359 & +0.80 & 2.008 & 1.009 & +0.8 \\
mc7:116.9 & -312.4250 & -312.4248 & +1.61 & 2.011 & 1.011 & +1.6 \\
\hline \multicolumn{7}{|c|}{$\mathrm{U}_{3} \mathrm{O}_{3}$ trioxo models } \\
\hline mc8:153.5 & -420.2289 & -420.2318 & -23.38 & 3.766 & 1.765 & -11.7 \\
\hline mc9:154.5 & -420.2661 & -420.2665 & -3.22 & 3.763 & 1.763 & -1.6 \\
mc11:158.5 & -420.2583 & -420.2617 & -27.42 & 3.765 & 1.763 & -13.7 \\
mc12:161.5 & -420.7972 & -420.7978 & -4.84 & 3.766 & 1.766 & -2.4 \\
\hline
\end{tabular}

It is worth noting that whatever the considered core geometry distortion of the $\mathrm{U}_{2} \mathrm{O}_{2}$ and $\mathrm{U}_{3} \mathrm{O}_{3}$ models, the BS state is generally more stable that the HS one, which means that the AF character of the $\mathrm{U}_{\mathrm{x}} \mathrm{O}_{\mathrm{x}}$ core is kept and that it is a fundamental property of these magnetic cores. Moreover, it can be seen that in Table 6 the mc3 model exhibits a $J$ constant value of $-22.4 \mathrm{~cm}^{-1}$, which agrees well with the corresponding $J\left(-24.1 \mathrm{~cm}^{-1}\right)$ obtained for the actual dioxo system with the fixed X-ray core geometry (Table 5).

The most striking result in Table 6 is the decrease of the AF character as the UOU bond angle is increased for the dioxo $\mathrm{U}_{2} \mathrm{O}_{2} \mathrm{mc}(1-7)$ models, where the $J$ value diminishes in absolute value, predicting a nonmagnetic state for the mc5 model. Moreover, when increasing the UOU value angle up to 114.9 and $116.9^{\circ}$, it is found that the dioxo complex turns to be ferromagnetic.

The MO diagram of the dioxo mc3 model in its HS (triplet) state (figure 4), shows that the main U-oxo interactions are sustained by the $\sigma$ SOMO-10 numbered $192 \mathrm{~A}$ within the $\mathrm{U}_{2} \mathrm{O}_{2}$ core. Indeed, this MO involves significant contribution from both uranium $5 \mathrm{f}$ and oxo $\mathrm{O}(2 \mathrm{p})$ orbitals, in line with the super-exchange and the antiferromagnetic character of the complex. In Table 7, are reported the most relevant orbital contribution to the SOMO, SOMO-1 and SOMO-10 as a function of the UOU angles of the considered dioxo models. In the same table are included the $\mathrm{U}-\mathrm{O}\left(\mathrm{U}-\mathrm{O}_{\mathrm{ax}} / \mathrm{U}-\mathrm{O}_{\mathrm{eq}}\right)$ atom-atom overlap populations computed as the sum of the $\alpha$ and $\beta$ spins contributions, noting that the same value is obtained considering the HS or the BS state. 
Table 7: ZORA/B3LYP/TZP computed most relevant orbital contribution FMO to the dioxo models with UOU angle variation and dioxo $\mathrm{U}-\mathrm{O}_{\mathrm{ax}} / \mathrm{U}-\mathrm{O}_{\mathrm{eq}}$ atom-atom overlap populations.

\begin{tabular}{ccccc}
\hline \multirow{2}{*}{$\begin{array}{c}\text { UOU } \\
\left(^{\circ}\right.\end{array}$} & \% (6d/5f/U/dioxo) & & $\begin{array}{c}\text { atom-atom } \\
\text { overlap } \\
\text { populations }\end{array}$ \\
\cline { 2 - 5 } & SOMO (202A) & SOMO-1 (201A) & SOMO-10 (192A) & U-O ${ }_{\text {ax } / U-O_{\text {eq }}}$ \\
\hline 97.9 & $0 / 92.7 / 92.7 / 0$ & $0 / 92.4 / 92.4 / 0$ & $0 / 28.2 / 33.3 / 13.6$ & $0.211 / 0.062$ \\
103.9 & $0 / 89.3 / 89.3 / 0$ & $0 / 88.2 / 88.2 / 0$ & $0 / 23.9 / 26.5 / 9.75$ & $0.212 / 0.088$ \\
$\mathbf{1 0 5 . 9}$ & $\mathbf{0 / 9 0 . 7 / 9 0 . 7 / 0}$ & $\mathbf{0 / 8 7 . 3 / 8 7 . 3 / 0}$ & $\mathbf{0 / 2 5 . 1 / 2 9 . 5 / 1 3 . 1}$ & $\mathbf{0 . 2 4 8 / 0 . 1 0 6}$ \\
110.9 & $0 / 89.5 / 89.5 / 0$ & $0 / 90.4 / 90.4 / 0$ & $0 / 26.0 / 30.9 / 10.1$ & $0.227 / 0.092$ \\
113.9 & $0 / 89.6 / 89.6 / 0$ & $0 / 91.3 / 91.3 / 0$ & $0 / 24.8 / 28.7 / 4.8$ & $0.221 / 0.088$ \\
114.9 & $0 / 89.5 / 89.5 / 0$ & $0 / 90.2 / 90.2 / 0$ & $0 / 11.4 / 15.1 / 3.4$ & $0.116 / 0.038$ \\
116.9 & $0 / 87.8 / 87.8 / 0$ & $0 / 78.5 / 78.5 / 0$ & $0 / 11.4 / 15.1 / 2.1$ & $0.054 / 0.022$
\end{tabular}

As it can be seen in Table 7, there is no significant change in the SOMO and SOMO-1 compositions with the UOU angle variation, as these MOs remain mainly metallic being in average $90 \% 5 \mathrm{f}$ orbitals, as shown by the percentages $\%(6 \mathrm{~d} / 5 \mathrm{f} / \mathrm{U} / \mathrm{dioxo})$ weights. The most striking result is the composition of the SOMO-10 (\#192A) which is traducing the U-O interaction within the $\mathrm{U}_{2} \mathrm{O}_{2}$ core. It is worth noting that the oxygen atoms weight in the SOMO10 decreases from 13.1 to $2.1 \%$ with the increase of the UOU angle from 105.9 (X-ray value) to $116.9^{\circ}$. This is correlating well with the decrease of the exchange coupling constant $J$ (see Table 6) which switches from AF to ferromagnetic character as the UOU angle increases. We must keep in mind that in our me dioxo models, the $\mathrm{U}-\mathrm{O}_{\mathrm{ax}} / \mathrm{U}-\mathrm{O}_{\text {eq }}$ bond lengths have been kept fixed to their X-ray values (1.942/2.384 $\mathrm{A})$. Moreover, regarding the effect of the UOU angle variation, we observe that the overlap populations reach their maximum value for the X-ray angle value. Furthermore, the computed $\mathrm{U}-\mathrm{O}_{\mathrm{ax}}$ atom-atom overlap population as a function of the UOU angle variation (Table 7) decreases drastically from 0.248 for the X-ray $\left(105.9^{\circ}\right)$ angle to 0.116 at the UOU angle of $114.9^{\circ}$ matching with the appearance of a weak ferromagnetic exchange coupling $\left(\mathrm{J}=+0.8 \mathrm{~cm}^{-1}\right)$ with the $\mathrm{U}_{2} \mathrm{O}_{2}$ core. The same trend is observed for the $\mathrm{U}-\mathrm{O}_{\mathrm{eq}}$ overlap population. These results are in the line with previous EHT study on bimetallic transition metal systems, ${ }^{89}$ reporting the influence of the metal-ligand-metal (M-L-M) bridge 
angle on the metal-ligand overlap and consequently on the coupling magnetic character; it was observed that as MLM bridged angle increases from 90 to $110^{\circ}$, the metal-like orbital overlap with ligand decreases. Furthermore, as reported, ${ }^{82}$ there is also a dependence of the relative energy of the symmetric $\left(\phi_{\mathrm{S}}\right)$ and antisymmetric $\left(\phi_{\mathrm{A}}\right)$ metal-ligand highest occupied MOs with the M-L overlap as the MLM angle varies.

Thus, in order to investigate possible magneto-structural correlations in our case, the HS/BS energy variation of the SOMO, SOMO-1 and SOMO-10 levels as a function of the UOU angle in HS/BS state, is reported in the Table 8. Furthermore, the (SOMO - SOMO-1) energy gap in the HS spin state is also included in this Table 8.

Table 8: ZORA/B3LYP/TZP SOMOs energy $(\mathrm{eV})$ variation and energy difference $\Delta \mathrm{E}$ between SOMO and SOMO-1, with the UOU $\left(^{\circ}\right)$ angle in HS/BS states of the dioxo species.

\begin{tabular}{ccccccccc}
\hline $\begin{array}{c}\text { UOU } \\
\left({ }^{\circ}\right)\end{array}$ & \multicolumn{9}{c}{ HS } & \multicolumn{9}{c}{ BS } & \multicolumn{2}{c}{ HS/BS } & \\
& $\begin{array}{c}\text { SOMO } \\
(202 \mathrm{~A})\end{array}$ & $\begin{array}{c}\text { SOMO-1 } \\
(201 \mathrm{~A})\end{array}$ & $\begin{array}{c}\text { SOMO } \\
\alpha(201 \mathrm{~A})\end{array}$ & $\begin{array}{c}\text { SOMO-1 } \\
\beta(201 \mathrm{~A})\end{array}$ & $\begin{array}{c}\text { SOMO-10 } \\
(192 \mathrm{~A})\end{array}$ & $\begin{array}{c}\Delta \mathrm{E}_{\mathrm{HS}} \\
(\mathrm{eV})\end{array}$ & $\begin{array}{c}\mathrm{J} \\
\left(\mathrm{cm}^{-1}\right)\end{array}$ \\
\hline 97.9 & -4.455 & -4.606 & -4.528 & -4.543 & $-6.959 /-6.873$ & 0.151 & -56.1 \\
103.7 & -4.424 & -4.552 & -4.486 & -4.493 & $-6.965 /-6.932$ & 0.128 & -31.2 \\
$\mathbf{1 0 5 . 9}$ & $\mathbf{- 4 . 5 3 0}$ & $\mathbf{- 4 . 5 9 5}$ & $\mathbf{- 4 . 5 6 2}$ & $\mathbf{- 4 . 5 6 4}$ & $\mathbf{- 6 . 9 8 0 / - 6 . 8 4 0}$ & $\mathbf{0 . 0 6 5}$ & $\mathbf{- 2 2 . 4}$ \\
110.9 & -4.444 & -4.481 & -4.464 & -4.461 & $-7.026 /-6.876$ & 0.037 & -3.2 \\
113.9 & -4.561 & -4.594 & -4.442 & -4.583 & $-7.035 /-6.873$ & 0.033 & 0 \\
114.9 & -4.432 & -4.461 & -4.573 & -4.583 & $-7.169 /-7.030$ & 0.029 & +0.8 \\
116.9 & -4.469 & -4.494 & -4.468 & -4.493 & $-7.125 /-6.902$ & 0.025 & +1.6 \\
\hline
\end{tabular}

The most relevant result is this energy difference $\Delta \mathrm{E}_{\mathrm{HS}}$ in the HS state which decreases when opening the UOU bond angle leading to the exchange coupling switching from AF to ferromagnetic. The considered SOMO and SOMO-1 (\# 202A and 201A) are mainly the symmetric (S) and anti-symmetric (A) combination of the $\mathrm{U}\left(\mathrm{f}_{\mathrm{xyz}}\right)-\mathrm{U}\left(\mathrm{f}_{\mathrm{xyz}}\right)$ 5f orbitals. As previously reported, ${ }^{82}$ the relative $\Delta \mathrm{E}=\mathrm{E}_{\mathrm{S}}-\mathrm{E}_{\mathrm{A}}$ energies in bimetallic transition metal complexes, as a function of M-L-M bond angle variation, determine the magnetic character of the metal-metal exchange coupling. Indeed, it was observed that the AF coupling should be expected as this energy difference $\Delta \mathrm{E}$ increases and one should expect a ferromagnetic coupling when such $\Delta \mathrm{E}$ value is equal or tends towards zero. ${ }^{77}$ Moreover, as exemplified by the $\mathrm{Cu}_{2}(\mu-$ 
$\mathrm{OH}) \mathrm{CI}_{4}{ }^{2-}$ system, the relative energy $\Delta \mathrm{E}$ between the two $\phi_{\mathrm{S}}$ and $\phi_{\mathrm{A}} \mathrm{MOs}$ as a function of the $\mathrm{MOM}$ angle varying from 90 to $110^{\circ}$ reveals a $\mathrm{AF} / \mathrm{F}$ crossover point occurring at $107^{\circ} .{ }^{82}$

For our part, as it can be seen in the Table 8 , the $\Delta$ Es reproduce satisfactorily this trend, and reveal that AF exchange coupling is related to a high $\Delta \mathrm{E}$ energy difference $\left(\mathrm{J}=-56 \mathrm{~cm}^{-1}\right.$ for $\Delta \mathrm{E}=0.151 \mathrm{eV})$. On the contrary, the exchange coupling tends to the ferromagnetic character with small $\Delta \mathrm{E}$ values $\left(\mathrm{J}=+1.6 \mathrm{~cm}^{-1}\right.$ for $\left.0.025 \mathrm{eV}\right)$. So, as expected the UOU bond angle value affecting the $\Delta \mathrm{E}$ quantity, determines the magnetic character. The variation of the magnetic coupling constant is also related to the bridging dioxo orbital weight and the atom-atom $\mathrm{U}-\mathrm{O}$ overlap populations (Table 7) which decrease drastically (vide supra) with the increase of the UOU angle from 97.9 to $114.9^{\circ}$, a high overlap population being correlated to magnetic superexchange.

\section{Spin Densities Analysis:}

Spin densities play a key role for the qualitative understanding of ferromagnetic and $\mathrm{AF}$ exchange coupling. In d-transition metal magneto-chemistry, some mechanisms have been proposed to explain the exchange coupling between the magnetic centers by spin polarization, spin delocalization ${ }^{131,132}$ or super-exchange phenomena as expressed early by O. Kahn. ${ }^{133}$ Concerning our target systems, we shall consider first the dioxo $\left[\mathrm{UO}_{2}(\mathrm{dbm})_{2} \mathrm{~K}(18 \mathrm{C} 6)\right]_{2}$ and trioxo $\left[\mathrm{UO}_{2}(\mathrm{~L})\right]_{3}$ actual complexes with X-ray core geometry fixed, in order to understand and rationalize their ubiquitous $\mathrm{AF}$ character. Then, a comparison with the $\mathbf{m c 3}$ and mc10 models which led to $J$ constants similar to the actual complexes ones $\left(-22.4\right.$ and $\left.-7.2 \mathrm{~cm}^{-1}\right)$ will be done. The obtained spin density maps (difference between the $\alpha$ and $\beta$ electron densities) are displayed on Figure 7. 


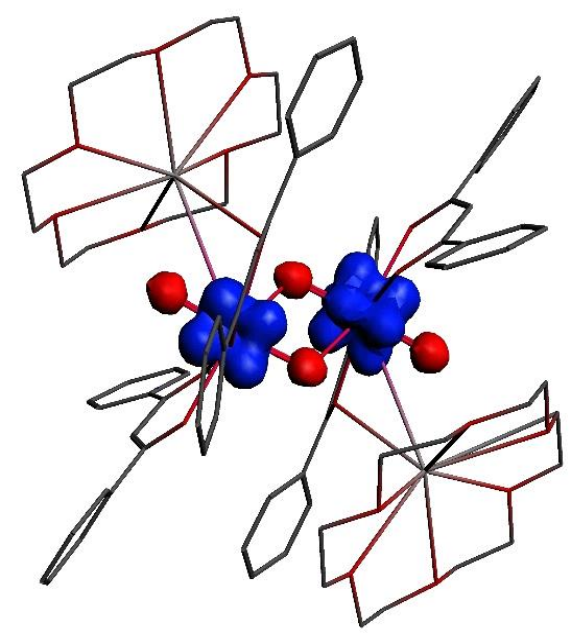

(HS)

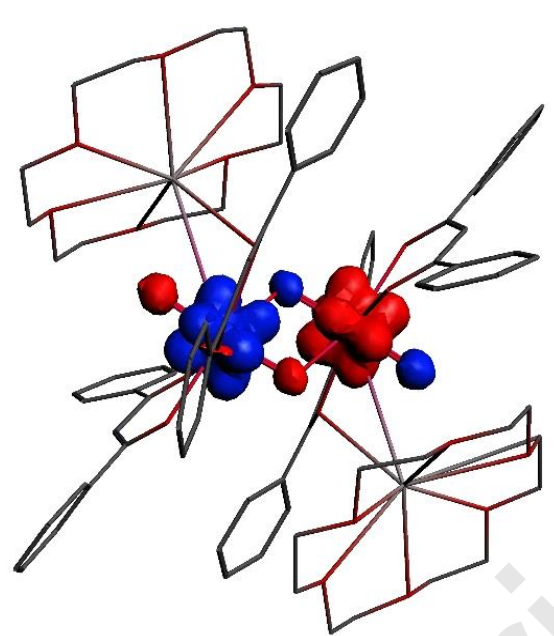

(BS)

Figure 7: ZORA/B3LYP/TZP spin density distributions for the HS (triplet) and BS states of $\left[\mathrm{UO}_{2}(\mathrm{dbm})_{2} \mathrm{~K}(18 \mathrm{C} 6)\right]_{2}$ (blue color: positive and red color: negative spin density). The isodensity surface corresponds to a value of $0.0025 \mathrm{e} \mathrm{bohr}^{-3}$.

We note that both HS and BS states exhibit well localized spin densities on the two magnetic diuranium(V) centers with non-negligible values on their nearest $\mathrm{O}_{\text {oxo }}$ and $\mathrm{O}_{1,2}$ neighbors. Interestingly, the spin density maps show that the uranyl(V)-oxo bridging ligands contribute to the exchange coupling mechanism, with significant spin densities. It is worth noting that for the HS state the spin of the two oxo groups is symmetrically polarized by the two $\mathrm{U}^{\mathrm{V}}$ spin carriers. On the contrary, for the BS state, the bridging oxo ligands are differently polarized according to the electron spin of the magnetic center. This is likely to highlight the crucial spin polarization role of the bridging oxo ligands favoring antiferromagnetic coupling of the $\left[\mathrm{UO}_{2}(\mathrm{dbm})_{2} \mathrm{~K}(18 \mathrm{C} 6)\right]_{2}$ complex. Furthermore, it can be seen in Table 9, where are reported the relevant spin populations, that both NPA (Natural Population Analysis) and MDC (Multipole Derived Charges) analyses lead to equivalent results, although NPA gives metal spin population greater than 1 contrarily to the MDC analysis. It can be noticed, that a small dissymmetry appears for the uranium spin densities of the binuclear complex, in the HS state but not for its BS state.

Table 9: ZORA/B3LYP/TZP NPA spin populations for the HS and BS states of $\left[\mathrm{UO}_{2}(\mathrm{dbm})_{2} \mathrm{~K}(18 \mathrm{C} 6)\right]_{2}$ model complex with X-ray fixed core. Atoms are numbered as indicated on Figure 2. 


\begin{tabular}{ccc|cc}
\hline & & & & \\
\hline Atoms & $\mathrm{HS}$ & $\mathrm{BS}$ & $\mathrm{HS}$ & $\mathrm{BS}$ \\
\hline $\mathrm{U}_{1}$ & 1.054 & -1.052 & 0.829 & -0.826 \\
$\mathrm{U}_{2}$ & 1.054 & 1.052 & 0.829 & 0.826 \\
$\mathrm{O}_{\text {oxo1 }}$ & -0.040 & 0.031 & 0.039 & -0.001 \\
$\mathrm{O}_{\text {oxo2 }}$ & -0.040 & -0.031 & 0.039 & 0.001 \\
$\mathrm{O}_{1}$ & $-0.054 /$ & 0.054 & 0.005 & -0.006 \\
$\mathrm{O}_{2}$ & $-0.054 /$ & -0.054 & 0.005 & 0.006 \\
\hline
\end{tabular}

The obtained spin density for the trioxo $\left[\mathrm{UO}_{2}(\mathrm{~L})\right]_{3}$ complex with fixed $\mathrm{U}_{3} \mathrm{O}_{3}$ core, are reported in Table 10 and depicted on Figure 8.

Table 10: ZORA/B3LYP NPA spin populations for HS and BS states of the $\left[\mathrm{UO}_{2}(\mathrm{~L})\right]_{3}$ model complex with fixed $\mathrm{U}_{3} \mathrm{O}_{3}$ core.

\begin{tabular}{ccc|cc}
\hline \multirow{2}{*}{ Atoms $^{\mathrm{a}}$} & \multicolumn{2}{c|}{ NPA } & \multicolumn{2}{c}{ MDC } \\
\cline { 2 - 5 } & $\mathrm{HS}$ & $\mathrm{BS}$ & $\mathrm{HS}$ & $\mathrm{BS}$ \\
\hline $\mathrm{U}_{1}$ & 1.101 & -1.111 & 0.904 & -0.914 \\
$\mathrm{U}_{2}$ & 1.101 & 1.110 & 0.907 & 0.914 \\
$\mathrm{U}_{3}$ & 1.101 & 1.107 & 0.908 & 0.912 \\
$\mathrm{O}_{\text {oxo1 }}$ & -0.040 & 0.031 & 0.047 & 0.006 \\
$\mathrm{O}_{\text {oxo2 }}$ & -0.039 & -0.042 & 0.048 & 0.049 \\
$\mathrm{O}_{\text {ox03 }}$ & -0.039 & -0.031 & 0.050 & -0.006 \\
$\mathrm{O}_{1}$ & -0.044 & 0.059 & -0.005 & 0.003 \\
$\mathrm{O}_{2}$ & -0.044 & -0.059 & -0.008 & -0.006 \\
$\mathrm{O}_{3}$ & -0.044 & -0.059 & -0.008 & -0.008 \\
\hline
\end{tabular}

${ }^{\mathrm{a}}$ In this table, atoms are numbered as indicated on Figure 2. 


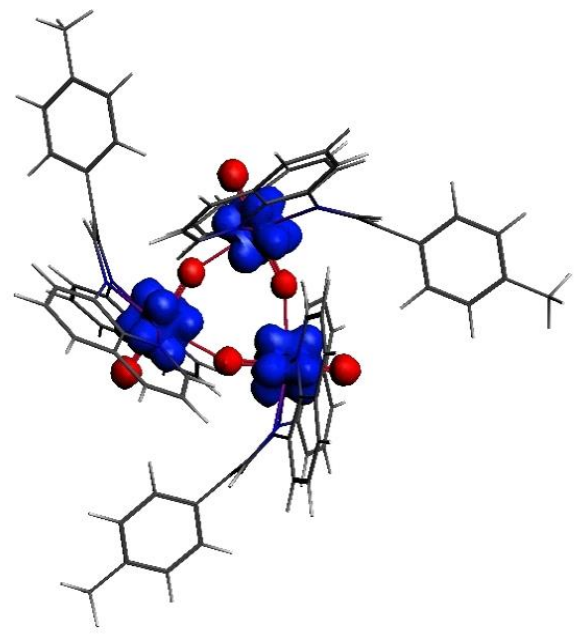

(HS)

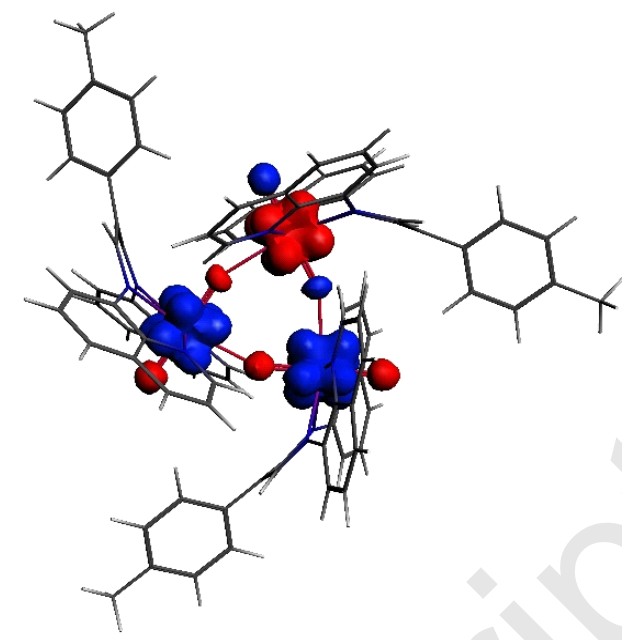

(BS)

Figure 8: ZORA/B3LYP/TZP spin density distributions for the HS (quintet) and BS states of $\left[\mathrm{UO}_{2}(\mathrm{~L})\right]_{3}$ (blue color: positive and red color: negative spin density). The isodensity surface corresponds to a density value of $0.0025 \mathrm{e} \mathrm{bohr}^{-3}$.

Similarly to the dioxo picture (Figure 7) the HS trioxo state shows that the three oxo spin density are symmetrically polarized by the trimetallic $\mathrm{U}^{\mathrm{V}}$ centers. In opposite, the BS state exhibit differently polarized bridging oxo ligands. Indeed, it can be seen in Table 9, where are reported the relevant NPA and MDC spin populations, that a small dissymmetry appears for the uranium and oxo-bridging spin densities of the trioxo complex, but not for the outer oxo ligands.

Regarding the reliability of the small models to describe the observed AF exchange coupling in the actual complexes, namely mc3 $\left[\mathrm{UO}_{2}(\text { methanate })_{2} \mathrm{~K}\right]_{2}$ and mc10 $\left[\mathrm{UO}_{2}(\mathrm{~L})\right]_{3}(\mathrm{~L}=$ bis(Me)malondiiminate) models bearing the $\mathrm{X}$-ray $\mathrm{U}_{\mathrm{x}} \mathrm{O}_{\mathrm{x}}$ core geometries of the real complexes, it can be seen that they provide very similar spin density maps (Figures S2 and S3). These magneto-structural properties sustain once again the crucial role of the $\mathrm{U}_{\mathrm{x}} \mathrm{O}_{\mathrm{x}}$ core geometry featuring the AF exchange coupling.

\section{Conclusions}

In summary, the exchange coupling constant between uranium centers in the $\left[\mathrm{UO}_{2}(\mathrm{dbm})_{2} \mathrm{~K}(18 \mathrm{C} 6)\right]_{2}$ binuclear and $\left[\mathrm{UO}_{2}(\mathrm{~L})\right]_{3}$ trinuclear complexes with diamond and triangle shaped cores, exhibiting the $5 \mathrm{f}^{1}-5 \mathrm{f}^{1}$ and $5 \mathrm{f}^{1}-5 \mathrm{f}^{1}-5 \mathrm{f}^{1}$ electron configurations respectively, have been investigated theoretically using relativistic DFT ZORA/B3LYP computations combined with the broken symmetry (BS) approach. The antiferromagnetic (AF) character observed experimentally is confirmed by the calculations. 
The computations revealed that the magnetic exchange coupling within such oxo-bridged complexes exhibiting Cation-Cation Interactions (CCI) is more sensitive to changes in the $\mathrm{U}_{\mathrm{x}} \mathrm{O}_{\mathrm{x}}$ core geometry than to changes in the coordination environment around the magnetic core. The magnetic exchange coupling $J$ constants have been estimated as $J=-24.1 \mathrm{~cm}^{-1}$ for the dioxo $\left[\mathrm{UO}_{2}(\mathrm{dbm})_{2} \mathrm{~K}(18 \mathrm{C} 6)\right]_{2}$ and $J=-7.2 \mathrm{~cm}^{-1}$ for the trioxo $\left[\mathrm{UO}_{2}(\mathrm{~L})\right]_{3}$ complexes. It is noteworthy that the considered complexes as well as the used simplified models bearing the actual $\mathrm{U}_{\mathrm{x}} \mathrm{O}_{\mathrm{x}}$ core geometries reproduce satisfactorily the AF exchange coupling. The influence of small changes of the U---U distance and UOU angles on the coupling constants has been investigated. Although the robust AF exchange coupling within the $U_{x} O_{x}$ cores is generally maintained when small variations of the UOU angle are applied, a weak ferromagnetic character appears in the dioxo species when this angle is higher than $114^{\circ}$ the $\mathrm{X}$-ray measured angle being equal to $105.9^{\circ}$. In the case of the dioxo species it is found that the magnetic character is related to the energy difference between the two highest metallic SOMO and SOMO-1. A high energy difference determining the AF coupling as it is the case for the actual dioxo complex, whereas a nearly zero one determines the ferromagnetic coupling. The latter situation appears when the UOU angle is increased. These energies are themselves driven by the overlap population within the dioxo core, a high metal-oxygen overlap population being correlated to the super-exchange occurrence.

The bonding interactions within these cores have been analyzed using several approaches including the NPA and the QTAIM analyses. The combined structural and electronic analysis data, were corroborated by the MO analysis sustaining that the metal-metal electronic communication favoring magnetic exchange interactions in such diuranium(V) and triuranium(V) systems, originates partially from the covalently bound bridging oxo groups in the $\mathrm{U}_{2} \mathrm{O}_{2}$ diamond-core and $\mathrm{U}_{3} \mathrm{O}_{3}$ triangle-core.

\section{ASSOCIATED CONTENT}

\section{Supplementary Information}

- Scheme S1: Molecular structure of $\left[\mathrm{UO}_{2}(\mathrm{dbm})_{2}\right]^{2-}$

-NPA and QTAIM analyses

- Figure S1: MO diagram of the BS state of the mc10 model

- Figures S2 and S3: spin density distributions for the mc3 and mc10 models. 
- DFT optimized geometries

\section{ACKNOWLEDGMENTS}

The authors are grateful to Frères Mentouri University of Constantine 1 (Algeria) for providing computing facilities. Are also acknowledged, the Algerian PRFU project (2018-2022: grant $N^{\circ}$ B00L01UN250120180015), French GENCI-IDRIS and GENCICINES programs for an allocation of computing time (Grant No. 2017-2018-080649), the COST CM-1006 action and the Swiss National Science Foundation grant number 200021_162430.

\section{References}

1. Sessoli, R.; Gatteschi, D.; Caneschi, A.; Novak, M. A. Magnetic bistability in a metal-ion cluster. Nature 1993, 365, 141-143.

2. Christou, G.; Gatteschi, D.; Hendrickson D. N.; Sessoli, R. Single-Molecule Magnets. Mater. Res. Bull. 2000, 25, 66-71.

3. Single-Molecule Magnets and Related Phenomena, Ed. Winpenny, R. Structure and Bonding Book Series, (Structure vol. 122) Springer-Verlag Berlin Heidelberg, 2006.

4. Gatteschi, D.; Sessoli, R.; Villain, J. Molecular Nanomagnets, Oxford University Press, Oxford, 2006.

5. Jeon, I.-R.; Clerac, R. Controlled association of single-molecule magnets (SMMs) into coordination networks: towards a new generation of magnetic materials. Dalton Trans. 2012, 41, 9569-9586.

6. Sessoli, R.; Powell, A.K. Strategies towards single molecule magnets based on lanthanide ions. Coord. Chem. Rev. 2009, 253, 2328-2341.

7. Demir, S.; Jeon, I.-R.; Long, J.R.; Harris, T.D. Radical ligand-containing single-molecule magnets. Coord. Chem. Rev. 2015, 289-290, 149-176.

8. Woodruff, D.N.; Winpenny, R.E.P.; Layfield, R.A. Lanthanide single-molecule magnets. Chem. Rev. 2013, 113, 5110-5148.

9. Leuenberger, M.N.; Loss, D. Quantum computing in molecular magnets. Nature 2001, 410, 789-793. 
10. Mannini, M.; Pineider, F.; Sainctavit, P.; Danieli, C.; Otero, E.; Sciancalepore, C.; Talarico, A.M.; Arrio, M.-A.; Cornia, A.; Gatteschi, D.; Sessoli, R. Magnetic memory of a single-molecule quantum magnet wired to a gold surface. Nat. Mater. 2009, 8, 194 197.

11. Habib, F.; Murugesu, M. Lessons learned from dinuclear lanthanide nano-magnets. Chem. Soc. Rev. 2013, 42, 3278-3288.

12. Goodwin, C. A. P.; Ortu, F.; Reta, D.; Chilton, N. F.; Mills, D. P. Molecular magnetic hysteresis at 60 kelvin in dysprosocenium. Nature, 2017, 548, 439-442.

13. Sanvito, S. Molecular spintronics. Chem. Soc. Rev. 2011, 40, 3336-3355.

14. Clemente-Juan, J.M.; Coronado, E.; Gaita-Arino, A. Magnetic polyoxometalates: from molecular magnetism to molecular spintronics and quantum computing. Chem. Soc. Rev. 2012, 41, 7464-7478.

15. Guo, F.S.; Day, B.M.; Chen, Y.C.; Tong, M.L.; Mansikkamäki, A.; Layfield, R. A. A Dysprosium Metallocene Single-Molecule Magnet Functioning at the Axial Limit. Angew. Chem. Int. Ed. 2017, 56, 11445-11449.

16. Guo, F.S.; Day, B.M.; Chen, Y.C.; Tong, M.L.; Mansikkamäki, A.; Layfield, R.A. Magnetic hysteresis up to 80 kelvin in a dysprosium metallocene single-molecule magnet. Science 2018, 362, 1400-1403.

17. Rinehart, J. D.; Fang, M.; Evans, W.; Long, J. R. A $\mathrm{N}_{2}{ }^{3-}$ Radical-Bridged Terbium Complex Exhibiting Magnetic Hysteresis at 14 K. J. Am. Chem. Soc. 2011, 133, 14236-9.

18. Rinehart, J. D.; Fang, M.; Evans, W.; Long, J. R. Strong exchange and magnetic blocking in $\mathrm{N}_{2}{ }^{3-}$-radical-bridged lanthanide complexes. Nat. Chem. 2011, 3, 538-542.

19. Rinehart, J. D.; Long, J. R. Exploiting Single-Ion Anisotropy in the Design of f-Element Single-Molecule Magnets. Chem. Sci. 2011, 2, 2078-2085.

20. Demir, S.; Zadrozny, J. M.; Nippe, M.; Long, J. R. Exchange Coupling and Magnetic Blocking in Bipyrimidyl Radical-Bridged Dilanthanide Complexes. J. Am. Chem. Soc. 2012, 134, 18546-9.

21. Gould, C. A.; Darago, L.E.; Gonzalez, M. I.; Demir, S.; Long, J. R. A Trinuclear RadicalBridged Lanthanide Single-Molecule Magnet. Angew. Chem. Int. Ed. 2017, 56, 10103 10107.

22. Rinehart, J. D.; Long, J. R. Slow Magnetic Relaxation in a Trigonal Prismatic Uranium(III) Complex. J. Am. Chem. Soc. 2009, 131, 12558-12559. 
23. Rinehart, J. D.; Harris, T. D.; Kozimor, S. A.; Bartlett, B. M.; Long, J. R. Magnetic Exchange Coupling in Actinide-Containing Molecules. Inorg. Chem. 2009, 48, $3382-3395$.

24. Meihaus, K. R.; Long, J. R. Actinide-Based Single-Molecule Magnets. Dalton Trans. 2015, 44, 2517-2528.

25. Liddle, S. T.; van Slageren, J. Improving f-element single molecule magnets. Chem. Soc. Rev. 2015, 44, 6655-6668.

26. McAdams, S. G.; Ariciu, A.-M.; Kostopoulos, A. K.; Walsh, J. P.S.; Tuna, F. Molecular single-ion magnets based on lanthanides and actinides: Design considerations and new advances in the context of quantum technologies. Coord. Chem. Rev. 2017, 346, 216239.

27. Magnani, N.; Caciuffo, R. Future Directions for Transuranic Single Molecule Magnets. Inorganics 2018, 6, 26.

28. Actinides Single-Molecule Magnets in Lanthanides and Actinides in Molecular Magnetism, Eds: Layfield, R.A. and Murugesu, M. Wiley-VCH Verlag GmbH \& Co. KGaA. 2015, pp. 315-339.

29. Rinehart, J. D.; Meihaus, K. R.; Long, J. R. Observation of a Secondary Slow Relaxation

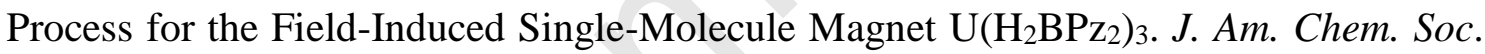
2010, 132, 7572-7573.

30. Meihaus, K. R.; Rinehart, J. D.; Long, J. R. Dilution-Induced Slow Magnetic Relaxation and Anomalous Hysteresis in Trigonal Prismatic Dysprosium(III) and Uranium(III) Complexes. Inorg. Chem. 2011, 50, 8484-8489.

31. Rinehart, J. D.; Long, J. R. Slow magnetic relaxation in homoleptic trispyrazolylborate complexes of neodymium(III) and uranium(III). Dalton Trans. 2012, 41, 13572-4.

32. Le Roy, J. J.; Gorelsky, S. I.; Korobkov, I.; Murugesu, M. Slow Magnetic Relaxation in U(III) and $\mathrm{Nd}(\mathrm{III})$ Cyclooctatetraenyl Complexes. Organometallics 2015, 34, 1415-1418.

33. Antunes, M.A.; Pereira, L.C.; Santos, I.C.; Mazzanti, M.; Marcalo, J.; Almeida, M. $\mathrm{U}\left(\mathrm{Tp}\left(\mathrm{Me}_{2}\right)\right)(2)($ bipy)(+): A Cationic Uranium(III) Complex with Single-MoleculeMagnet Behavior. Inorg. Chem. 2011, 50, 9915-9917.

34. King, D.M.; Tuna, F.; McMaster, J.; Lewis, W.; Blake, A.J.; McInnes, E.J.; Liddle, S.T. Single-Molecule Magnetism in a Single-Ion Triamidoamine Uranium (V) Terminal Mono-Oxo Complex. Angew. Chem. Int. Ed. 2013, 52, 4921-4924. 
35. Meihaus, K.R.; Minasian, S.G.; Lukens Jr., W.W.; Kozimor, S.A.; Shuh, D.K.; Tyliszczak, T.; Long, J.R. Influence of Pyrazolate vs. N-Heterocyclic Carbene Ligands on the Slow Magnetic Relaxation of Homoleptic Trischelate Lanthanide(III) and Uranium(III) Complexes. J. Am. Chem. Soc. 2014, 136, 6056-6068

36. Spivak, M.; Vogiatzis, K.D.; Cramer, C.J.; de Graaf, C.; Gagliardi, L. Quantum Chemical Characterization of Single Molecule Magnets Based on Uranium. J. Phys. Chem. A 2017, 121, 1726-1733.

37. Gaggioli, C. A.; Gagliardi, L. Theoretical Investigation of Plutonium-Based SingleMolecule Magnets. Inorg. Chem. 2018, 57, 8098-8105.

38. Pereira, L.C.; Camp, C.; Coutinho, J.T.; Chatelain, L.; Maldivi, P.; Almeida, M.; Mazzanti, M. Single-Molecule-Magnet Behavior in Mononuclear Homoleptic Tetrahedral Uranium(III) Complexes. Inorg. Chem. 2014, 53, 11809-11811.

39. Mills, D. P.; Moro, F.; McMaster, J.; van Slageren, J.; Lewis, W.; Blake, A. J.; Liddle, S. T. A Delocalized Arene-Bridged Diuranium Single-Molecule Magnet. Nat. Chem. 2011, $3,454-460$

40. Kindra, D. R.; Evans, W. J. Magnetic Susceptibility of Uranium Complexes. Chem. Rev. 2014, 114, 8865-8882.

41. Hohloch, S.; Pankhurst, J.R.; Jaekel, E.E.; Parker, B.F.; Lussier, D.J.; Garner, M.E.; Booth, C.H.; Love, J.B.; Arnold, J. Benzoquinonoid-bridged dinuclear actinide complexes. Dalton Trans. 2017, 46, 11615-11625

42. Chatelain, L.; Walsh, J. P. S.; Pécaut, J.; Tuna, F.; Mazzanti, M. Self-Assembly of a 3d5f Trinuclear Single-Molecule Magnet from a Pentavalent Uranyl Complex. Angew. Chem. Int. Ed. 2014, 53, $13434-13438$.

43. Chatelain, L.; Tuna, F.; Pécaut, J.; Mazzanti, M. Synthesis and SMM behaviour of trinuclear versus dinuclear $3 \mathrm{~d}-5 \mathrm{f}$ uranyl(v)-cobalt(ii) cation-cation complexes. Dalton Trans. 2017, 46, 5498-5502.

44. Chatelain, L.; Pécaut, J.; Tuna, F.; Mazzanti, M. Heterometallic $\mathrm{Fe}_{2}{ }_{2}{ }_{-}-\mathrm{U}^{\mathrm{V}}$ and $\mathrm{Ni}_{2}{ }^{\mathrm{II}}-\mathrm{U}^{\mathrm{V}}$ Exchange-Coupled Single-Molecule Magnets: Effect of the 3d Ion on the Magnetic Properties. Chem. Eur. J. 2015, 21, 18038-18042.

45. Chatelain, L.; Tuna, F.; Pécaut, J.; Mazzanti, M. A zig-zag uranyl(v)-Mn(ii) single chain magnet with a high relaxation barrier. Chem. Commun. 2015, 51, 11309-11312.

46. Mougel, V.; Chatelain, L.; Pecaut, J.; Caciuffo, R.; Colineau, E.; Griveau, J. C.; Mazzanti, M. Uranium and Manganese Assembled in a Wheel-Shaped Nanoscale Single-Molecule Magnet with High Spin-Reversal Barrier. Nat. Chem. 2012, 4, 1011-1017. 
47. Kozimor, S.A.; Bartlett, B.M.; Rinehart, J.D.; Long, J.R. Magnetic Exchange Coupling in Chloride-Bridged 5f-3d Heterometallic Complexes Generated via Insertion into a Uranium(IV) Dimethylpyrazolate Dimer. J. Am. Chem. Soc. 2007, 129, 10672-10674.

48. Mougel, V.; Chatelain, L.; Hermle, J.; Caciuffo, R.; Colineau, E.; Tuna, F.; Magnani, N.; De Geyer, A.; Pécaut, J.; Mazzanti, M. A uranium-based $\mathrm{UO}_{2}(+)-\mathrm{Mn}^{2+}$ single-chain magnet assembled trough cation-cation interactions. Angew. Chem., Int. Ed. 2014, 53, 819-823.

49. Patel, D.; Tuna, F.; McInnes, E.J.; McMaster, J.; Lewis, W.; Blake, A.J.; Liddle, S.T. A triamido-uranium(V) inverse-sandwich $10 \pi$-toluene tetraanion arene complex. Dalton Trans. 2013, 42, 5224-5227.

50. Schelter, E. J.; Veauthier, J. M.; Graves, C. R.; John, K. D.; Scott, B. L.; Thompson, J. D.; Pool-Davis-Tournear, J. A.; Morris, D. E.; Kiplinger, J. L. 1,4-dicyanobenzene as a scaffold for the preparation of bimetallic actinide complexes exhibiting metal-metal communication. Chem. Eur. J. 2008, 14, 7782-7790.

51. Spencer, L. P.; Schelter, E.J.; Yang, P.; Gdula, R. L.; Scott, B. L.; Thompson, J. D.; Kiplinger, J. L.; Batista, E. R.; Boncella, J. M. Cation-cation interactions, magnetic communication, and reactivity of the pentavalent uranium ion $\left[\mathrm{U}(\mathrm{NtBu})_{2}\right]^{+}$. Angew . Chem., Int. Ed. 2009, 48, 3795-3798.

52. Lukens, W. W.; Walter, M. D. Quantifying Exchange Coupling in f-Ion Pairs Using the Diamagnetic Substitution Method. Inorg. Chem. 2010, 49, 4458-4465.

53. Newell, B. S.; Rappé, A. K.; Shores, M. P. Experimental Evidence for Magnetic Exchange in Di- and Trinuclear Uranium(IV) Ethynylbenzene Complexes. Inorg. Chem. 2010, 49, 1595-1606.

54. Fox, A. R.; Arnold, P. L.; Cummins, C. C. Uranium Nitrogen Multiple Bonding: Isostructural Anionic, Neutral, and Cationic Uranium Nitride Complexes Featuring a Linear U=N=U Core. J. Am. Chem. Soc. 2010, 132, 3250-3251.

55. Larch, C. P.; Cloke, F. G. N.; Hitchcock, P. B. Activation and reduction of diethyl ether by low valent uranium: Formation of the trimetallic, mixed valence uranium oxo species $\left[\mathrm{U}\left(\mathrm{Cp}^{\mathrm{RR}}\right)(\mu-\mathrm{I})_{2}\right]_{3}\left(\mu^{3}-\mathrm{O}\right)\left(\mathrm{Cp}^{\mathrm{RR}}=\mathrm{C}_{5} \mathrm{Me}_{5}, \mathrm{C}_{5} \mathrm{Me}_{4} \mathrm{H}, \mathrm{C}_{5} \mathrm{H}_{4} \mathrm{SiMe}_{3}\right)$. Chem. Commun. 2008, 82-84.

56. Falcone, M.; Barluzzi, L.; Andrez, J.; Tirani, F. F.; Zivkovic, I.; Fabrizio, A. The role of bridging ligands in dinitrogenreduction and functionalization by uranium multimetallic complexes. Nat. Chem. 2019, 11, 154-160. 
57. Barluzzi, L.; Chatelain, L.; Fadaei-Tirani, F.; Zivkovic, I.; Mazzanti, M., Facile Nfunctionalization and strong magnetic communication in a diuranium(V) bis-nitride complex. Chem. Sci. 2019, 10, 3543 - 3555.

58. Tatebe, C. J.; Kiernicki, J. J.; Higgins, J. A.; Ward, A. L.; Natoli, S. N.; Langford, J. C.; Clark, C. L.; Zeller, M.; Wenthold, P.; Shores, M. P.; Walensky, J. R.; Bart, S. C. Investigation of the Electronic Structure of Aryl-Bridged Dinuclear U(III) and U(IV) Compounds. Organometallics 2019, 38, 1031-1040.

59. Arnold, P. L.; Dutkiewicz, M.S.; Zegke, M.; Walter, O.; Apostolidis, C.; Hollis, E.; Pécharman, A.-F.; Magnani, N.; Griveau, J.-C.; Colineau, E.; Caciuffo, R.; Zhang, X.; Schreckenbach, G.; Love. J. B., Subtle Interactions and Electron Transfer between UIII, NpIII, or PuIII and Uranyl Mediated by the Oxo Group. Angew. Chem. Int. Ed. 2016, 55, 12797-12801.

60. Myers, A. J.; Rungthanaphatsophon, P. A.; Behrle, C.; Vilanova, S. P.; Kelley, S. P.; Lukens, W. W.; Walensky. J. R., Structure and properties of [(4,6$\left.\left.\mathrm{tBu}_{2} \mathrm{C}_{6} \mathrm{H}_{2} \mathrm{O}\right)_{2} \mathrm{Se}\right]_{2} \mathrm{An}(\mathrm{THF})_{2}, \mathrm{An}=\mathrm{U}, \mathrm{Np}$, and their reaction with p-benzoquinone. Chem. Commun. 2018, 54, 10435

61. Arnold, P. L.; Love, J. B.; Patel, D. Pentavalent uranyl complexes. Coord. Chem. Rev. 2009, 253, 1973-1978.

62. Gardner, B. M.; King, D. M.; Tuna, F.; Wooles, A. J.; Chilton, N. F.; Liddle, S. T. Assessing Crystal Field and Magnetic Interactions in Diuranium $\mathrm{U}^{\mathrm{IV}}-\mathrm{E}-\mathrm{U}^{\mathrm{IV}}$ cores $(\mathrm{E}=$ S, Se, Te). Chem. Sci. 2017, 8, 6207-6217.

63. Nocton, G.; Horeglad, P.; Pécaut, J.; Mazzanti, M. Polynuclear cation-cation complexes of pentavalent uranyl: Relating stability and magnetic properties to structure. J. Am. Chem. Soc. 2008, 130, 16633-16645.

64. Arnold, P. L.; Jones, G. M.; Odoh, S. O.; Schreckenbach, G.; Magnani, N.; Love, J. B. Strongly coupled binuclear uranium-oxo complexes from uranyl oxo rearrangement and reductive silylation. Nat. Chem. 2012, 4, 221-227.

65. Mougel, V.; Horeglad, P.; Nocton, G.; Pécaut, J.; Mazzanti, M. Innentitelbild: Stable Pentavalent Uranyl Species and Selective Assembly of a Polymetallic Mixed-Valent Uranyl Complex by Cation-Cation Interactions. Angew. Chem. 2009, 121, 8532-8532.

66. Almond, P. M.; Skanthakumar, S.; Soderholm, L.; Burns, P. C. Cation-Cation Interactions and Antiferromagnetism in $\mathrm{Na}\left[\mathrm{Np}(\mathrm{V}) \mathrm{O}_{2}(\mathrm{OH})_{2}\right]$ : Synthesis, Structure, and Magnetic Properties. Chem. Mater. 2007, 19, 280-285 
67. Jones, G. M.; Arnold, P. L.; Love, J. B. Oxo-Group-14-Element Bond Formation in Binuclear Uranium(V) Pacman Complexes. Chem. Eur. J. 2013, 19, 10287-10295.

68. Adelani, P. O.; Burns, P. C. One-Dimensional Uranyl-2,2'-bipyridine Coordination Polymer with Cation-Cation Interactions: $\left(\mathrm{UO}_{2}\right)_{2}\left(2,2^{\prime}\right.$-bpy $)\left(\mathrm{CH}_{3} \mathrm{CO}_{2}\right)(\mathrm{O})(\mathrm{OH})$. Inorg. Chem. 2012, 51, 11177-83.

69. Mougel, V.; Pecaut, J.; Mazzanti, M. New polynuclear U(IV)-U(V) complexes from U(IV) mediated uranyl(V) Disproportionation. Chem. Commun. 2012, 48, 868-870.

70. Lam, O. P.; Heinemann, F. W.; Meyer, K. Activation of elemental S, Se and Te with uranium(III): Bridging $\mathrm{U}-\mathrm{E}-\mathrm{U}(\mathrm{E}=\mathrm{S}, \mathrm{Se})$ and diamond-core complexes $\mathrm{U}-(\mathrm{E})_{2}-\mathrm{U}(\mathrm{E}=$ O, S, Se, Te). Chem. Sci. 2011, 2, 1538-1547.

71. Schmidt, A- C.; Heinemann, F. W.; Lukens, Jr., W. W.; Meyer, K. Molecular and Electronic Structure of Dinuclear Uranium Bis- $\mu$-Oxo Complexes with Diamond Core Structural Motifs. J. Am. Chem. Soc. 2014, 136, 11980-11993.

72. Chatelain, L.; Mougel, V.; Pécaut, J.; Mazzanti, M. Magnetic communication cationcation trimer of pentavalent uranyl. Chem. Sci. 2012, 3, 1075-1079.

73. Mougel, V.; Horeglad, P.; Nocton, G.; Pecaut, J.; Mazzanti, M. Cation-cation complexes of pentavalent uranyl: From disproportionation intermediates to stable clusters. Chem. Eur. J. 2010, 16, 14365-14377.

74. Teyar, B.; Belkhiri, L.; Costuas, K.; Boucekkine, A.; Meyer, K. Electronic Structure and Magnetic Properties of Dioxo-Bridged Diuranium Complexes with Diamond-Core Structural Motifs: A Relativistic DFT Study. Inorg. Chem. 2016, 55, 2870-2881.

75. Noodleman, L. Valence bond description of antiferromagnetic coupling in transition metal dimers. J. Chem. Phys. 1981, 74, 5737.

76. Noodleman, L.; Davidson, E. R. Ligand spin polarization and antiferromagnetic coupling in transition metal dimers. Chem. Phys. 1986, 109, 131-143.

77. Mouesca, J. M.; Noodleman, L.; Case, D.A.; Lamotte, B. Spin Densities and Spin Coupling in Iron-Sulfur Clusters: A New analysis of hyperfine coupling constants. Inorg. Chem. 1995, 34, 4347-4359.

78. Noodleman, L. J.; Peng, C. Y.; Case, D. A.; Mouesca, J. M. Orbital interactions, electron delocalization and spin coupling in iron-sulfur clusters.Coord. Chem. Rev. 1995, 144, 199-244.

79. Meskaldji, S.; Belkhiri, A.; Belkhiri, L.; Boucekkine, A.; Ephritikhine, M. Magnetic exchange coupling in imido bimetallic uranium(V) complexes. A relativistic DFT study. C. R. Chim. 2012, 15, 184-191. 
80. Meskaldji, S.; Zaiter, A.; Belkhiri, L.; Boucekkine, A. A relativistic DFT study of magnetic exchange coupling in ketimide bimetallic uranium(IV) complexes. Theor. Chem. Acc. 2012, 131, 1151-1159.

81. Paez-Hernandez, D.; Murillo-Lopez, J. A.; Arratia-Perez, R. Optical and Magnetic Properties of the Complex Bis(dicyclooctatetraenyl)diuranium. A Theoretical View. Organometallics 2012, 31, 6297-6304.

82. Hay, P. J.; Thibeault, J. C.; Hoffmann, R. Orbital Interactions in Metal Dimer Complexes. J. Am. Chem. Soc. 1975, 97, 4884-4899.

83. Døssing, A. Recent advances in the coordination chemistry of hydroxo-bridged complexes of chromium(III). Coord. Chem. Rev. 2014, 280, 38-53.

84. Ouilia, S.; Beghidja, C.; Beghidja, A.; Belkhiri, L.; Rabu, P. Synthesis, crystal structure, magnetic properties and DFT calculations of new dihydroxo-bridged binuclear chromium(III) based on monodentate mixed ligand. Inorg. Chim. Acta 2018, 476, 54-60.

85. Rajaraman, G.; Totti, F.; Bencini, A.; Caneschi, A.; Sessoli, R.; Gatteschi, D. Density functional studies on the exchange interaction of a dinuclear $\mathrm{Gd}(\mathrm{III})-\mathrm{Cu}(\mathrm{II})$ complex: Method assessment, magnetic coupling mechanism and magneto-structural correlations. Dalton Trans. 2009, 3153-3161.

86. Salmon, L.; Thuéry, P.; Rivière, E.; Marrot, J.; Girerd, J.-J.; Ephritikhine, M. Syntheses, X-Ray Crystal Structures, and Magnetic Properties of Novel Linear $\mathrm{M}_{2}{ }_{2} \mathrm{U}^{\mathrm{IV}}$ Complexes $(\mathrm{M}=\mathrm{Co}, \mathrm{Ni}, \mathrm{Cu}, \mathrm{Zn})$. Chem. Eur. J. 2002, 8, 773-783.

87. Salmon, L.; Thuéry, P.; Rivière, E.; Girerd, J.-J.; Ephritikhine, M. Versatility of the nature of the magnetic $\mathrm{Cu}(\mathrm{II})-\mathrm{U}(\mathrm{IV})$ interaction. Syntheses, crystal structures and magnetic properties of $\mathrm{Cu}_{2} \mathrm{U}$ and $\mathrm{CuU}$ compounds. Dalton Trans. 2003, 2872-2880.

88. Salmon, L.; Thuéry, P.; Rivière, E.; Girerd, J.-J.; Ephritikhine M. Structure, and Magnetic Behavior of a Series of Trinuclear Schiff Base Complexes of $5 f\left(\mathrm{U}^{\mathrm{IV}}, \mathrm{Th}^{\mathrm{IV}}\right)$ and $3 \mathrm{~d}\left(\mathrm{Cu}^{\mathrm{II}}, \mathrm{Zn}^{\mathrm{II}}\right)$ Ions. Inorg. Chem. 2006, 45, 83-93.

89. Monreal, M. J.; Diaconescu, P. L. Weak Interaction between Iron and Uranium in Uranium Alkyl Complexes Supported by Ferrocene Diamide Ligands. Organometallics 2008, 27, 1702-1706.

90. ADF2017.103 release, SCM; Theoretical Chemistry; Vrije University: Amsterdam, The Netherlands; http://www.scm.com.

91. Fonseca Guerra, C.; Snijders, J. G.; te Velde, G.; Baerends, E. J. Towards an order-N DFT method. Theor. Chem. Acc. 1998, 99, 391-403. 
92. te Velde, G.; Bickelhaupt, F. M.; van Gisbergen, S. J. A.; Guerra, C. F.; Baerends, E. J.; Snijders, J. G.; Ziegler, T. Chemistry with ADF. J. Comput. Chem. 2001, 22, 931-967.

93. van Lenthe, E.; Baerends, E. J.; Snijders, J. G. Relativistic regular two-component Hamiltonians. J. Chem. Phys. 1993, 99, 4597-4610.

94. van Lenthe, E.; Baerends, E. J.; Snijders, J. G. Relativistic total energy using regular approximations. J. Chem. Phys. 1994, 101, 9783-9792.

95. van Lenthe, E.; Ehlers, A.; Baerends, E. J. Geometry optimizations in the zero order regular approximation for relativistic effects. J. Chem. Phys. 1999, 110, 8943-8953.

96. van Lenthe, E.; Snijders, J. G.; Baerends, E. J. The zero-order regular approximation for relativistic effects: The effect of spin-orbit coupling in closed shell molecules. J. Chem. Phys. 1996, 105, 6505-6516.

97. Becke, A.D. Density-functional exchange-energy approximation with correct asymptotic behaviour. Phys. Rev. A 1988, 38, 3098-3100.

98. Perdew, J. P. Density-functional approximation for the correlation energy of the inhomogeneous electron gas. Phys. Rev. B 1986, 33, 8822-8824.

99. Perdew, J. P.; Wang, Y. Accurate and simple analytic representation of the electron-gas correlation energy. Phys. Rev. B 1992, 45, 13244.

100. Bouzidi, Y.; Belkhiri, L.; Ephritikhine, M.; Halet, J.-F.; Boucekkine, A. Cyanide linkage isomerism in cerium(III) and uranium(III) complexes. A relativistic DFT study. $J$. Organomet. Chem. 2017, 847, 82-89.

101. Hervé, A.; Bouzidi, Y.; Berthet, J.-C.; Belkhiri, L.; Thuéry, P.; Boucekkine, A.; Ephritikhine, M. U ${ }^{\mathrm{III}}-\mathrm{CN}$ versus $\mathrm{U}^{\mathrm{IV}}-\mathrm{NC}$ Coordination in Tris(silylamide) Complexes. Inorg. Chem. 2015, 54, 2474-2490.

102. Cavigliasso, G.; Kaltsoyannis, N. On the Paucity of Molecular Actinide Complexes with Unsupported Metal-Metal Bonds: A Comparative Investigation of the Electronic Structure and Metal-Metal Bonding in $\mathrm{U}_{2} \mathrm{X}_{6}\left(\mathrm{X}=\mathrm{Cl}, \mathrm{F}, \mathrm{OH}, \mathrm{NH}_{2}, \mathrm{CH}_{3}\right)$ Complexes and d-Block Analogues. Inorg. Chem. 2006, 45, 6828-6839.

103. Schelter, E. J.; Yang, P.; Scott, B. L.; Thompson, J. D.; Martin, R. L.; Hay, P. J.; Morris, D. E.; Kiplinger, J. L. Systematic Studies of Early Actinide Complexes: Uranium(IV) Fluoroketimides. Inorg. Chem. 2007, 46, 7477-7488.

104. Gaunt, A. J.; Reilly, S. D.; Enriquez, A. E.; Scott, B. L.; Ibers, J. A.; Sekar, P.; Ingram, K. I. M.; Kaltsoyannis, N.; Neu, M. P. Experimental and Theoretical Comparison of Actinide and Lanthanide Bonding in $\mathrm{M}\left[\mathrm{N}\left(\mathrm{EPR}_{2}\right)_{2}\right]_{3}$ Complexes $(\mathrm{M}=\mathrm{U}, \mathrm{Pu}, \mathrm{La}, \mathrm{Ce} ; \mathrm{E}=$ $\mathrm{S}, \mathrm{Se}, \mathrm{Te} ; \mathrm{R}=\mathrm{Ph}, \mathrm{iPr}, \mathrm{H})$. Inorg. Chem. 2008, 47, 29-41. 
105. Graves, C. R.; Yang, P.; Kozimor, S. A.; Vaughn, A. E.; Clark, D. L.; Conradson, S. D.; Schelter, E. J.; Scott, B. L.; Thompson, J. D.; Hay, P. J.; Morris, D. E.; Kiplinger, J. L. Experimental and Theoretical Comparison of Actinide and Lanthanide Bonding in $\mathrm{M}\left[\mathrm{N}\left(\mathrm{EPR}_{2}\right)_{2}\right]_{3}$ Complexes $(\mathrm{M}=\mathrm{U}, \mathrm{Pu}, \mathrm{La}, \mathrm{Ce} ; \mathrm{E}=\mathrm{S}, \mathrm{Se}, \mathrm{Te} ; \mathrm{R}=\mathrm{Ph}, \mathrm{iPr}, \mathrm{H}) . J . A m$. Chem. Soc. 2008, 130, 5272-5285.

106. Belkhiri, L.; Le Guennic, B.; Boucekkine, A. DFT investigations of the magnetic properties of actinide complexes."Special Issue of Magnetic Properties of Complexes of Actinide Elements." Magnetochemistry 2019, 5, 15.

107. Becke, A. D. Density-functional thermochemistry. III. The role of exact exchange. J. Chem. Phys. 1993, 98, 5648-5652.

108. Lee, C.; Yang, W.; Parr, R. G. Development of the Colle-Salvetti correlation-energy formula into a functional of the electron density. Phys. Rev. B: Condens. Matter Mater. Phys. 1988, 37, 785-789.

109. Caballol, R.; Castell, O.; Ilias, F.; Moreira, I. P.; Malrieu, J. P. Remarks on the Proper Use of the Broken Symmetry Approach to Magnetic Coupling. J. Phys. Chem. A 1997, $101,7860-7866$.

110. Figgis, B. N.; Hitchman, M. A. Ligand Field Theory and its Applications, Wiley, 2000.

111. Onishi, T.; Yamaki, D.; Yamaguchi, K.; Takano, Y. Theoretical calculations of effective exchange integrals by spin projected and unprojected broken-symmetry methods. I. Cluster models of -type solids. J. Chem. Phys. 2003, 118, 9747-9761.

112. Shoji, M.; Koizumi, K.; Kitagawa, Y.; Kawakami, T.; Yamanaka, S.; Okumura, M.; Yamaguchi, K. A general algorithm for calculation of Heisenberg exchange integrals J in multi-spin systems. Chem. Phys. Lett. 2006, 432, 343-347.

113. Ruiz, E.; Cano, J.; Alvarez, S.; Alemany, P. Broken symmetry approach to calculation of exchange coupling constants for homobinuclear and heterobinuclear transition metal complexes. J. Comput. Chem. 1999, 20, 1391-1400.

114. Ruiz, E.; Rodríguez-Fortea, A.; Cano, J.; Alvarez, S.; Alemany, P. About the calculation of exchange coupling constants in polynuclear transition metal complexes. J. Comput. Chem. 2003, 24, 982-989.

115. Mayer, I. Charge, bond order and valence in the ab initio SCF theory. Chem. Phys. Lett. 1983, 7, 270.

116. Nalewajski, R. F.; Mrozek, J. Modified valence indices from the two-particle density matrix. Int. J. Quant. Chem. 1994, 51, 187. 
117. Nalewajski, R. F.; Mrozek, J.; Michalak, A. Two-electron valence indices from the KohnSham orbitals. Int. J. Quant. Chem. 1997, 61, 589.

118. La Macchia, G.; Bryanda, M.; Gagliardi, L. Quantum Chemical Calculations Predict the Diphenyl Diuranium Compound [PhUUPh] To Have a Stable ${ }^{1} \mathrm{Ag}$ Ground State. Angew. Chem., Int. Ed. 2006, 45, 6210-6213.

119. Zhou, J.; Sonnenberg, J. L.; Schlegel, H. B. Theoretical Studies of AnII2(C8H8)2 (An = Th, Pa, U, and Np) Complexes: The Search for Double-Stuffed Actinide Metallocenes. Inorg. Chem. 2010, 49, 6545-6551.

120. Roos, B. O.; Borin, A. C.; Gagliardi, L. Reaching the Maximum Multiplicity of the Covalent Chemical Bond. Angew. Chem., Int. Ed. 2007, 46, 1469-1472.

121. Monreal, M. J.; Carver, C. T.; Diaconescu, P. L. Redox Processes in a Uranium Bis $\left(1,1^{\prime}-\right.$ diamidoferrocene) Complex. Inorg. Chem. 2007, 46, 7226-7228.

122. Arnold, P. L.; Hollis, E.; White, F. J.; Magnani, N.; Caciuffo, R.; Love, J. B. SingleElectron Uranyl Reduction by a Rare-Earth Cation. Angew. Chem., Int. Ed. 2011, 50, 887890.

123. Reed, A. E.; Curtiss, L. A.; Weinhold, F. Intermolecular interactions from a natural bond orbital, donor-acceptor viewpoint. Chem. Rev. 1988, 88, 899-926.

124. Bader, R. F. W. Atoms in Molecules: A Quantum Theory. OUP: Oxford, 1990

125. Rodríguez, J. I.; Köster, A. M.; Ayers, P. W.; Santos-Valle, A.; Vela, A.; Merino. G. An efficient grid-based scheme to compute QTAIM atomic properties without explicit calculation of zero-flux surfaces. J. Comput. Chem. 2009, 30, 1082-1092.

126. Rodríguez, J. I.; Bader, R. F. W.; Ayers, P. W.; Michel, C.; Götz, A. W.; Bo, C. A high performance grid-based algorithm for computing QTAIM properties. Chem. Phys. Lett. 2009, 472, 149-152.

127. Mountain, A. R. E.; Kaltsoyannis, N. Do QTAIM metrics correlate with the strength of heavy element-ligand bonds? Dalton Trans. 2013, 42, 13477-13486.

128. Schnaars, D. D.; Gaunt, A. J.; Hayton, T. W.; Jones, M. B.; Kirker, I.; Kaltsoyannis, N. May, I.; Reilly, S. D.; Scott, B. L.; Wu, G. Bonding Trends Traversing the Tetravalent Actinide Series: Synthesis, Structural, and Computational Analysis of $\mathrm{An}^{\mathrm{IV}}$ (Aracnac)4 Complexes (An= Th, U, Np, Pu). Inorg. Chem. 2012, 51, 8557-8566.

129. Fryer-Kanssen, I.; Austin, J.; Kerridge, A. Topological study of bonding in aquo and bis (triazinyl) pyridine complexes of trivalent lanthanides and actinides: Does covalency imply stability? Inorg. Chem. 2016, 55, 10034-42. 
130. Reta, D.; Ortu, F.; Randall, S.; Mills, D.P.; Chilton, N.F.; Winpenny, R.E.P.; Natrajan, L.; Edwards, B.; Kaltsoyannis, N. The performance of density functional theory for the description of ground and excited state properties of inorganic and organometallic uranium compounds. J. Organomet. Chem. 2018, 857, 58-74.

131. Neese, F. Prediction of molecular properties and molecular spectroscopy with density functional theory: From fundamental theory to exchange-coupling. Coord. Chem. Rev. 2009, 253, 526-563.

132. Cirera, J.; Jiang, Y.; Qin, L.; Zheng, Y.-Z.; Li, G.; Wu, G.; Ruiz, E. Ferromagnetism in polynuclear systems based on non-linear $\left[\mathrm{Mn}_{2}^{\mathrm{II}} \mathrm{Mn}^{\mathrm{III}}\right]$ building blocks. Inorg. Chem. Front. 2016, 3, 1272-1279.

133. Kahn, O. Molecular magnetism, VCH, New York, 1993. 